3D bioprinting of graphene oxideincorporated cell-laden bone mimicking scaffolds for promoting scaffold fidelity, osteogenic differentiation and mineralization

\author{
Journal Article \\ Author(s): \\ Zhang, Jianhua; Eyisoylu, Hande; Qin, Xiao-Hua (D); Rubert, Marina (D); Müller, Ralph (D) \\ Publication date: \\ 2021-02 \\ Permanent link: \\ https://doi.org/10.3929/ethz-b-000467629
}

Rights / license:

Creative Commons Attribution 4.0 International

Originally published in:

Acta Biomaterialia 121, https://doi.org/10.1016/j.actbio.2020.12.026 


\title{
3D bioprinting of graphene oxide-incorporated cell-laden bone mimicking scaffolds for promoting scaffold fidelity, osteogenic differentiation and mineralization
}

\author{
Jianhua Zhang, Hande Eyisoylu, Xiao-Hua Qin, Marina Rubert, Ralph Müller* \\ Institute for Biomechanics, ETH Zurich, Leopold-Ruzicka-Weg 4, 8093 Zurich, Switzerland
}

\section{A R T I C L E I N F O}

\section{Article history:}

Received 7 September 2020

Revised 22 November 2020

Accepted 10 December 2020

Available online 14 December 2020

\section{Keywords:}

3D bioprinting

Graphene oxide

Scaffold fidelity

Osteogenic differentiation

ECM mineralization

\begin{abstract}
A B S T R A C T
Bioprinting is a promising technique for facilitating the fabrication of engineered bone tissues for patientspecific defect repair and for developing in vitro tissue/organ models for ex vivo tests. However, polymerbased ink materials often result in insufficient mechanical strength, low scaffold fidelity and loss of osteogenesis induction because of the intrinsic swelling/shrinking and bioinert properties of most polymeric hydrogels. Here, we developed a human mesenchymal stem cells (hMSCs)-laden graphene oxide (GO)/alginate/gelatin composite bioink to form 3D bone-mimicking scaffolds using a 3D bioprinting technique. Our results showed that the GO composite bioinks $(0.5 \mathrm{GO}, 1 \mathrm{GO}, 2 \mathrm{GO})$ with higher GO concentrations $(0.5,1$ and $2 \mathrm{mg} / \mathrm{ml})$ improved the bioprintability, scaffold fidelity, compressive modulus and cell viability at day 1 . The higher GO concentration increased the cell body size and DNA content, but the $2 \mathrm{GO}$ group swelled and had the lowest compressive modulus at day 42 . The $1 \mathrm{GO}$ group had the highest osteogenic differentiation of hMSC with the upregulation of osteogenic-related gene (ALPL, BGLAP, PHEX) expression. To mimic critical-sized calvarial bone defects in mice and prove scaffold fidelity, 3D cellladen GO defect scaffolds with complex geometries were successfully bioprinted. 1GO maintained the best scaffold fidelity and had the highest mineral volume after culturing in the bioreactor for 42 days. In conclusion, GO composite bioinks had better bioprintability, scaffold fidelity, cell proliferation, osteogenic differentiation and ECM mineralization than the pure alginate/gelatin system. The optimal GO group was $1 \mathrm{GO}$, which demonstrated the potential for 3D bioprinting of bone tissue models and tissue engineering applications.
\end{abstract}

\section{Statement of significance}

In this work, we developed a novel human mesenchymal stem cell (hMSC)-laden GO/alginate/ gelatin composite bioink to form 3D bone mimicking scaffolds. Our results showed that the GO composite bioinks with the optimal GO incorporation could improve bioprintability, scaffold fidelity, compressive modulus and cell viability. The higher GO concentration increased the cell body size and cell proliferation. The $1 \mathrm{GO}$ group $(1 \mathrm{mg} / \mathrm{ml})$ had the highest osteogenic differentiation of hMSC with the upregulation of osteogenic-related gene expression (ALPL, BGLAP, PHEX) at day 42. To mimic critical-sized calvarial bone defects in mice, 3D cell-laden GO defect scaffolds with complex geometries were successfully bioprinted. $1 \mathrm{GO}$ maintained the best scaffold fidelity and had the highest mineral volume after culturing in the bioreactor for 42 days.

(C) 2020 Acta Materialia Inc. Published by Elsevier Ltd.

This is an open access article under the CC BY license (http://creativecommons.org/licenses/by/4.0/)

\section{Introduction}

Bone fractures and bone diseases, such as osteoporosis, are a significant source of patient morbidity and place a staggering eco-

\footnotetext{
* Corresponding author.

E-mail address: ram@ethz.ch (R. Müller).
}

nomic burden on the healthcare system. Developing treatments for bone diseases and fracture healing require an understanding of the molecular mechanisms and mineral formation in bone developmental biology. 3D bioprinting techniques have shown promise for mimicking the structure of different tissues and organs through the precise placement of living cells and biomaterials in a layer-bylayer fashion [1]. 3D bioprinting has opened a perspective for bone 
defect bioprinting using patient-specific medical images [2] and for developing in vitro tissue/organ models for ex vivo tests [3]. One challenge in bone bioprinting remains supporting high cell viability after bioprinting and inducing extracellular matrix (ECM) mineralization in vitro. Different hydrogel materials (alginate, gelatin, gelatin methacryloyl, fibrinogen, etc.) and cell types have been successfully bioprinted for bone tissue engineering [4-6]. Among them, alginate-gelatin blend inks have been widely used for 3D bioprinting due to their biocompatibility, low cost and instant gelation at room temperature $[7,8]$. The thermosensitive properties of gelatin facilitate the initial stability of 3D bioprinted constructs [9]. Alginate polymer chains are crosslinked with $\mathrm{Ca}^{2+}$ after bioprinting to provide long-term mechanical strength. Our previous studies have shown that low-density alginate/gelatin $(0.8 \% \mathrm{alg})$ blend bioinks can maintain high cell viability $(>85 \%)$ and induce the osteogenic differentiation of human mesenchymal stem cells (hMSC) [10]. Significantly more mineralized tissue was formed in low-density $(0.8 \% \mathrm{alg})$ than high-density $(1.8 \%)$ alginate/gelatin scaffolds $\left(43.5 \pm 7.1 \mathrm{~mm}^{3}\right.$ vs $\left.22.6 \pm 6.0 \mathrm{~mm}^{3}\right)$ after culturing in osteogenic media for 42 days [28]. However, low-density alginate/gelatin ink solutions often result in moderate printability, insufficient mechanical strength, and low scaffold fidelity because of the intrinsic swelling and/or shrinking properties of alginate and gelatin. The scaffold fidelity and mechanical properties could be improved with higher density bioinks, such as by increasing alginate concentration, while increased viscosity suppressed cell viability and cell morphology [10]. Thus, the ability to design lowdensity alginate/gelatin-based bioinks with improved mechanical properties, scaffold fidelity and cell functions remains a challenge in 3D bioprinting for engineering bone tissues [11].

Organic/inorganic composite ink formulations have been studied to obtain the desired mechanical properties and gel behaviors for 3D bioprinting [12-14]. The most common inorganic particles added to hydrogels to prepare ink solutions are silica [15], laponite [16], hydroxyapatite [13], gold and silver nanoparticles [17]. However, these inorganic nanoparticles increase shear stress during the bioprinting processes, which may suppress cell viability and affect cell functions [11]. Nanoparticles may limit the diffusion of crosslinking reagents, resulting in inhomogeneous crosslinking of the relevant large 3D constructs [18]. Graphene oxide (GO), readily prepared from the oxidation of graphite, is an exciting nanomaterial for tissue engineering and regenerative medicine. GO has an atomically thin sheet with a large surface area and abundant hydrophilic functional groups (e.g., hydroxyl, epoxide and carbonyl) that allow a wide range of chemical modifications, and GO exhibits good absorption properties to various molecules and cations [19]. 2D studies have shown that GO improves hMSC adhesiveness and proliferation [20], cell growth [21-23] and osteogenic differentiation [23]. In 3D studies, many researchers have incorporated GO into hydrogel scaffolds, such as alginate [24,25], collagen [26] and gelatin methacrylate (GelMA) [27], and polymer chains were crosslinked to form a 3D GO hybrid scaffold. For example, Su et al. [27] incorporated GO into GelMA for the creation of cellladen graphene-embedding hydrogels and investigated the cellular responses in a 3D microenvironment. They demonstrated that GOGelMA hybrid hydrogels supported the spreading and alignment of fibroblasts with improved viability and proliferation. Choe et al. [25] have shown that the addition of GO $(0.05-1 \mathrm{mg} / \mathrm{ml})$ to $3 \%$ alginate significantly promoted the structural stability of the alginate bioink with reduced swelling during 5 days of incubation. However, 3D bioprinted hMSC-laden alginate composite scaffolds with higher alginate concentration resulted in higher mechanical properties, which inhibited cell spreading morphology and decreased the osteogenic differentiation of hMSC. Significantly more mineralized tissue was formed in soft scaffolds with lower alginate con- centration than in stiff scaffolds at day 42 [28]. Therefore, we hypothesized that the incorporation of GO with optimal concentration into the low-density alginate/gelatin-based bioink improves scaffold fidelity, while enhancing osteogenic differentiation of hMSCs, and increasing ECM mineralization for bone tissue engineering.

In this study, four different GO composite bioinks were prepared by mixing hMSC into an alginate/gelatin $(0.8 \% / 4.1 \%, \mathrm{w} / \mathrm{v})$ solution containing different GO concentrations $(0,0.5,1,2 \mathrm{mg} / \mathrm{ml})$. The influence of GO on bioprintability was first investigated by characterizing the shear thinning and shear recovery properties. The scaffold fidelity and mechanical properties of these varying GO composite scaffolds were studied by analyzing the changes in scaffold morphology and the compressive modulus on day 1, day 7 and day 42. To evaluate the influence of GO on cell behavior and function, we studied cell viability, cell morphology, DNA content, alkaline phosphatase (ALP) activity and osteogenic-related gene expression in a systematic fashion. 3D bioprinting offers exciting prospects for constructing 3D tissue/organ models, as it enables the reproducible, automated production of complex living tissues [3]. The 3D bioprinted tissue/organ model may prove useful as an ex vivo model for reducing animal usage and screening compounds or predicting toxicity. To go one step further, we aim to investigate if our model could mimic critical-sized calvarial bone defects in rodents using a 3D bioprinted cell-laden defect scaffold. More specifically, our goal was to assess the influence of different GO incorporations on the fidelity in printing more complex geometries such as a cylindrical defect in the 3D bioprinted scaffold, in which the mineral tissue formation in the defect will be hampered similarly to critically-sized bone defect models in animals. For this purpose, scaffold structure fidelity and the mineral tissue formation in a 3D bioprinted cylindrical defect scaffold over time were investigated in 42 days of culturing in the bone bioreactor through non-invasive in situ micro-computed tomography (micro-CT).

\section{Materials and methods}

\subsection{Inks preparation and GO characterization}

Details of the materials are provided in the supporting information. Four alginate/gelatin/GO composite ink solutions containing different GO concentrations, $0 \mathrm{mg} / \mathrm{ml}, 0.5 \mathrm{mg} / \mathrm{ml}, 1 \mathrm{mg} / \mathrm{ml}$ and $2 \mathrm{mg} / \mathrm{ml} \mathrm{GO}$, were named 0GO, 0.5GO, $1 \mathrm{GO}$ and 2GO, respectively. Alginate $(70.4 \mathrm{mg}, 0.8 \% \mathrm{w} / \mathrm{v})$ and gelatin $(360 \mathrm{mg}, 4.1 \% \mathrm{w} / \mathrm{v})$ were added to a homogeneous glycerol/ phosphate buffered saline (PBS) $(9.1 \% \mathrm{v} / \mathrm{v})$ solution to prepare the 0GO group as a control, as described previously [10]. The commercial GO product is a $5 \mathrm{mg} / \mathrm{ml}$ GO dispersion in water solution. To keep the same alginate and gelation concentrations in the four groups, different PBS concentrations, volumes and GO volumes were used to prepare different GO groups. The amounts of chemicals used for preparing the different alginate/gelatin/GO composite ink solutions are listed in Table 1. As an example, to prepare $1 \mathrm{GO}$ ink solution, $1.6 \mathrm{ml} \mathrm{GO}$ solution $(5 \mathrm{mg} / \mathrm{ml})$ was mixed with $5.6 \mathrm{ml} 1.29 \times$ PBS and $0.8 \mathrm{ml}$ glycerol solution to a homogeneous solution. Then, $70.4 \mathrm{mg}$ alginate and $360 \mathrm{mg}$ gelatin were dissolved in the above GO/PBS/glycerol solution at $50{ }^{\circ} \mathrm{C}$ in a water bath. The mixture was kept for $12 \mathrm{~h}$ to homogenize and fully dissolve the polymer and then pasteurized at $70{ }^{\circ} \mathrm{C}$ for $1 \mathrm{~h}$ before the next experiments.

The GO morphology was studied by using FEI Talos F200X transmission electron microscopy (TEM) (FEI Company, Hillsboro, USA). The spatial distribution of GO in the GO product and ink solutions was evaluated under a Zoom Stereomicroscope (Leica Microsystems, Heerbrugg, Switzerland). 
Table 1

Amounts of chemicals used for GO composite hydrogel preparation.

\begin{tabular}{llllll}
\hline Groups & Alginate $(\mathrm{mg})$ & Gelatin $(\mathrm{mg})$ & Glycerol $(\mathrm{ml})$ & PBS $(\mathrm{ml})$ & GO $(\mathrm{ml})$ \\
\hline 0GO & 70.4 & 360 & 0.8 & $7.2,1 \times$ PBS & 0 \\
0.5GO & 70.4 & 360 & 0.8 & $6.4,1.13 \times$ PBS & 0.8 \\
1GO & 70.4 & 360 & 0.8 & $5.6,1.29 \times$ PBS & 1.6 \\
2GO & 70.4 & 360 & 0.8 & $4,1.80 \times$ PBS & 3.2 \\
\hline
\end{tabular}
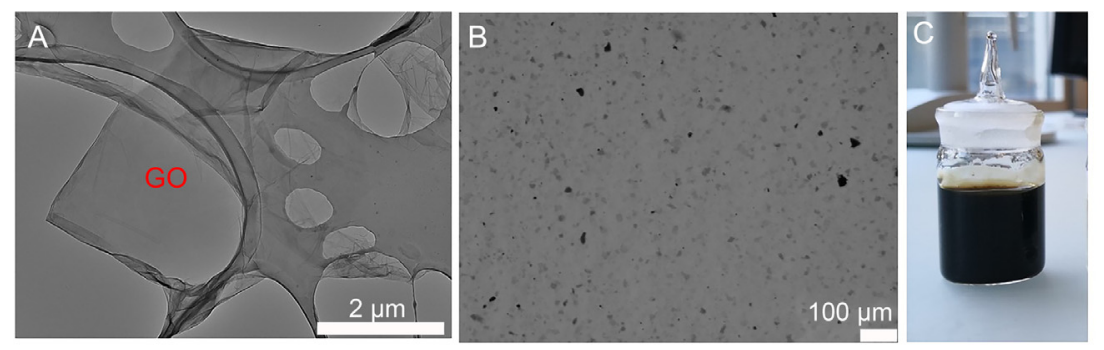

Alginate $(0.8 \% \mathrm{w} / \mathrm{v})$

Gelatin $(4.1 \% \mathrm{w} / \mathrm{v})$

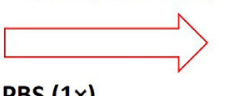

PBS (1x)

Glycerol $(9.1 \% \mathrm{v} / \mathrm{v})$
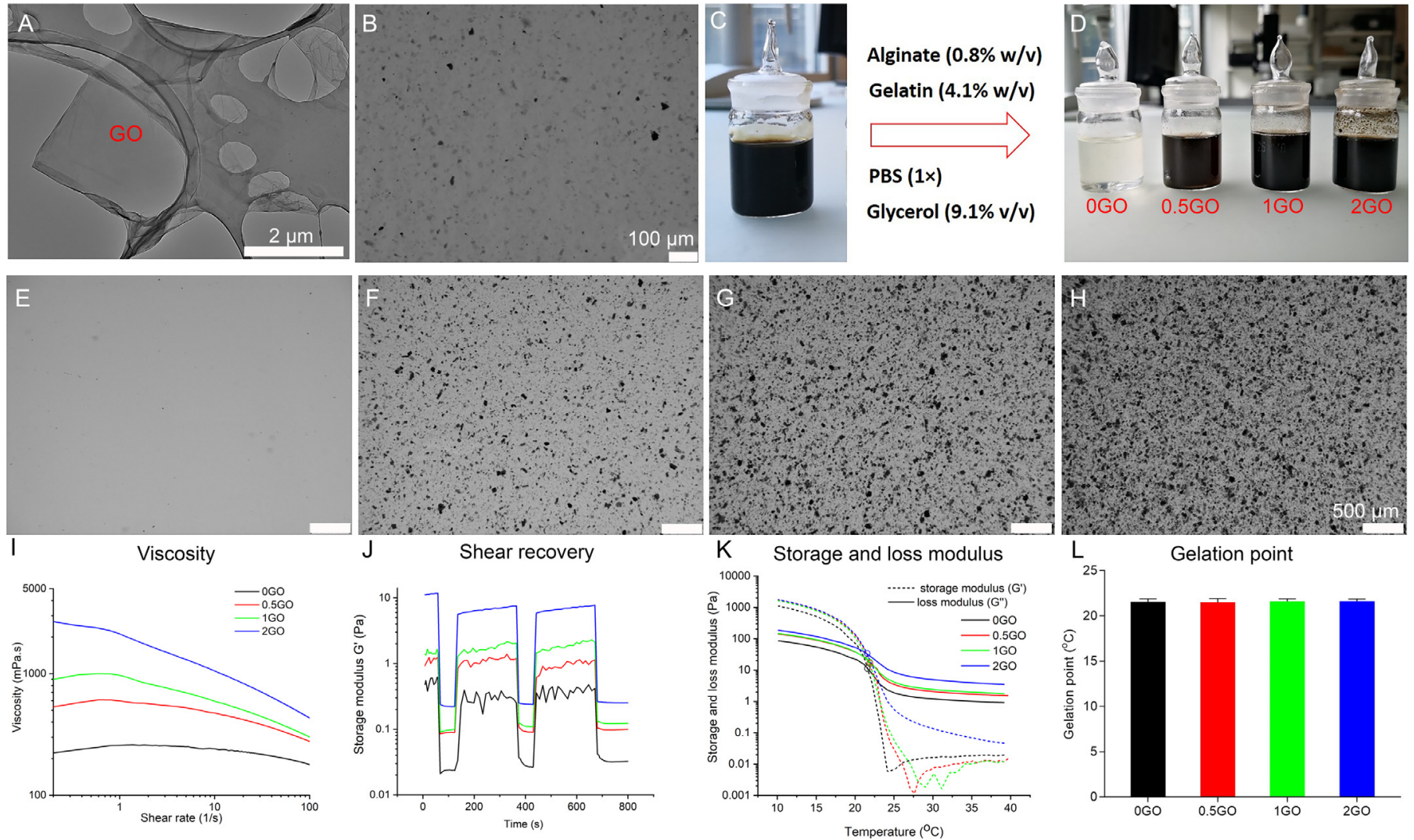

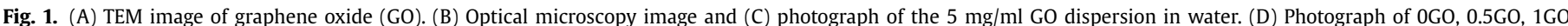

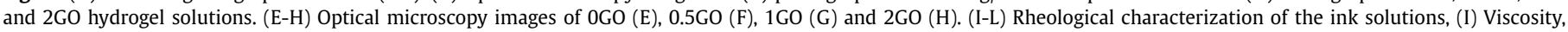
(J) Shear recovery, (K) Storage modulus and loss modulus change during cooling from $40{ }^{\circ} \mathrm{C}$ to $10{ }^{\circ} \mathrm{C}$, (L) Average gelation point of the four different $\mathrm{GO}$ inks ( $\mathrm{n}=3$ ).

\subsection{Rheology properties}

The rheological properties of the bioinks with different graphene oxides (0GO, 0.5GO, $1 \mathrm{GO}$ and 2GO) were measured using a HAAKE RheoStress 600 rheometer (Thermo Electron $\mathrm{GmbH}$, Karlsruhe, Germany). All measurements were performed in rotation with a cone-plate geometry with a diameter of $35 \mathrm{~mm}$, a cone-to-plate distance of $105 \mu \mathrm{m}$ and a cone angle of $2^{\circ}$. A liquid sample of $400 \mu \mathrm{l}$ bioink was placed on the plate at $37^{\circ} \mathrm{C}$. Viscosity and shear stress were measured at $37{ }^{\circ} \mathrm{C}$ with a rotatory test setup by varying the shear stress from $0.01 \mathrm{~s}^{-1}$ to $100 \mathrm{~s}^{-1}$. Shear recovery was performed under oscillation by measuring the storage modulus (G') and the loss modulus (G") at a frequency of $5 \mathrm{rad} \mathrm{s}^{-1}$ and a low strain of $0.5 \%$ for $60 \mathrm{~s}$. The strain was then increased to $500 \%$ at the same frequency for $60 \mathrm{~s}$ before returning to $0.5 \%$ strain for $240 \mathrm{~s}$. The thermoresponsive properties were analyzed by G' and G", which were assessed by oscillatory measurements at a frequency of $1 \mathrm{rad} / \mathrm{s}$ and 1\% strain. Before rheology measurements, the hydrogels were warmed up to $37{ }^{\circ} \mathrm{C}$. For the measurements, the hydrogels were cooled from $30{ }^{\circ} \mathrm{C}$ to $10{ }^{\circ} \mathrm{C}$ at a rate of $0.5{ }^{\circ} \mathrm{C} \mathrm{min}-1$. The gelation temperature was taken as the temperature when G' and G" were equal. All measurements were repeated three times to ensure consistency of the obtained results.

\subsection{Bioprinting}

$3 D$ printing of acellular GO scaffolds: In this study, a microextrusion-based two-syringe cell bioprinter (INKREDIBLE ${ }^{+}$, CELLINK, USA) was used to print the different alginate composite scaffolds. The scaffold model used was a lattice-rod structure $(10 \mathrm{~mm} \times 10 \mathrm{~mm} \times 2.5 \mathrm{~mm}$ ), which was converted into a G-Code file using Slic $3 \mathrm{r}$ with $0.17 \mathrm{~mm}$ layer height (15 layers), $0.76 \mathrm{~mm}$ pore size and $0.32 \mathrm{~mm}$ nozzle diameter. The ink solution was prepared by thoroughly mixing $1 \mathrm{ml}$ of hydrogel solution with $100 \mu \mathrm{l}$ DMEM with magnetic fish at $200 \mathrm{rpm} / \mathrm{min}$ for 1 minute at room temperature $\left(20^{\circ} \mathrm{C}\right)$. At room temperature, the ink solution is in a liquid state and cannot be extruded as a stable filament. Based on rheological measurements, the temperature for printability was set below the gelation point (Fig. 1L). To allow printability, the ink was introduced into a polyethylene injection cartridge $(5 \mathrm{cc})$ and cooled in a Styrofoam box containing ice for $8 \mathrm{~min}$. Reducing the temperature of the ink quickly and gaining fast gelation conferred the thermosensitivity property of the gelatin. The measured temperature of the bioink was of $10{ }^{\circ} \mathrm{C}$ before starting printing. The cartridge was fixed onto the printing device, and the G-Code model scaffold design was loaded into the printer's disk. Scaffolds were printed layer-by-layer via ink extrusion as fibers to create 3D scaf- 
folds on the bioprinter platform. Due to the lack of thermal control option, the bioprinter was surrounded with dry ice to keep the aircooled. During printing, air pressure was set to $50 \mathrm{kPa}$, speed was $2 \mathrm{~mm} / \mathrm{s}$, and nozzle size was $27 \mathrm{G}$. The temperature of the bioink was about $15{ }^{\circ} \mathrm{C}$ after printing and the printability temperature window of the bioink was at $10-15{ }^{\circ} \mathrm{C}$. Immediately after printing each scaffold, the scaffolds were crosslinked with $2 \%(\mathrm{w} / \mathrm{v}) \mathrm{CaCl}_{2}$ solution for $10 \mathrm{~min}$ to maintain structural integrity for long-term stability. To remove the excess $\mathrm{CaCl}_{2}$, the scaffold was washed 3 times in cell culture media, and each wash was 10 seconds. Scaffolds were cultured in osteogenic media (DMEM, 10\% FBS, $1 \% \mathrm{P} / \mathrm{S} / \mathrm{F}$, $50 \mu \mathrm{g} / \mathrm{ml} \mathrm{AA}, 100 \mathrm{nM}$ Dex, $10 \mathrm{mM} \beta$-GP) in an incubator $\left(37^{\circ} \mathrm{C}, 5 \%\right.$ $\mathrm{CO}_{2}$ ). The osteogenic media was changed every two days. To investigate the influence of temperature change during printing on printing performance and scaffold morphology, 15 acellular 0GO scaffolds were bioprinted in one day and scaffold morphology images were taken by a Zoom stereomicroscope (Leica Microsystems, Heerbrugg, Switzerland) on day 1.

3D bioprinting of cell-laden GO scaffolds: hMSCs (Lonza, Walkersville, MD, USA) were isolated from bone marrow aspirates and characterized as described previously [29]. P3 hMSCs were cultured in expansion media (DMEM, 10\% FBS, 1\% P/S/F, 1\% NEAA and $1 \mathrm{ng} / \mathrm{ml} \mathrm{bFGF})$ in an incubator $\left(37^{\circ} \mathrm{C}, 5 \% \mathrm{CO}_{2}\right)$ for 7 days. All cells were cultured in tissue culture polystyrene triple flasks, and cells at passage 4 were used for the subsequent experiments. After harvesting, the cells were resuspended at a density of 5 million cells in $100 \mu \mathrm{l}$ cell culture media (DMEM, 10\% FBS, 1\% P/S/F). The bioink was prepared by mixing the $100 \mu \mathrm{l}$ cell suspension with a $1 \mathrm{ml}$ ink solution. The scaffold model, 3D bioprinting, crosslinking and scaffold culturing processes were the same as described above for 3D printing of acellular scaffolds.

\subsection{Scaffold structure}

The influence of GO concentration on the structure of the 3D bioprinted scaffolds over time was observed using a Zoom stereomicroscope. Two-dimensional top view images of the 3D bioprinted acellular scaffolds $(n=3)$ were captured after incubation of the scaffold for 7 days in osteogenic media and under standard cell culture conditions $\left(37^{\circ} \mathrm{C}\right.$ and $5 \% \mathrm{CO}_{2}$ ). The morphological changes of the 3D bioprinted cell-laden scaffolds $(n=3)$ were observed on day 1, 7 and 42 of cell culture in osteogenic media. All images were taken at $1 \mathrm{x}$ magnification. Scaffold structure parameters, including pore size, filament diameter, pore area, and scaffold overall area, were manually measured and analyzed using ImageJ (National Institutes of Health, USA). Scaffold overall area is defined as the total surface that the scaffold occupies, including both the pore and filament spaces. This value is prescribed in the bioprinting process but due to shrinkage and swelling of the scaffold can differ from the prescribed value. The scaffold morphology parameters of the 3D bioprinted scaffolds on day 0 used the same parameters as the scaffold model. Pore size, filament diameter, and pore area were measured in at least ten different positions for each scaffold and averaged for a final value. The scaffold overall area was measured in three scaffolds per group and then averaged.

\subsection{Cell viability and cell area}

Cell viability in the 3D bioprinted cell-laden GO scaffolds was assessed using a LIVE/DEAD ${ }^{\circ}$ Viability/Cytotoxicity assay after 1, 7 and 42 days of culture in osteogenic media. After washing twice in PBS, samples were transferred to a $2 \mu \mathrm{M}$ Calcein-AM and $4 \mu \mathrm{M}$ ethidium homodimer (EthD-1) solution and cultured in a $\mathrm{CO}_{2}$ cell incubator for $40 \mathrm{~min}$. Then, the cell-laden scaffolds were thoroughly rinsed with PBS twice and kept on sterile chambered cover glasses (Lab-TekTM, Thermo Scientific) with $1.5 \mathrm{ml}$ cell culture media. Live cells emitted green fluorescent light and were visualized under the green fluorescent protein (GFP) channel (emission: $525 \mathrm{~nm}$ ). Dead cells emitted red fluorescent light and were visualized under the mCherry fluorescent protein channel (emission: $630 \mathrm{~nm}$ ). A confocal microscopy (Visitron Spinning Disk, Nikon Eclipse T1) was used to visualize live and dead cells, and six representative images of each scaffold were captured (magnification of 10x) for this purpose. Cell viability was calculated as the percentage of live cells as a fraction of the total cell count. Cell area was calculated using $\mathrm{Z}$ projection images, which were generated from $Z$-stack live/dead images. Z-stacks were taken at $10 \times$ magnification with a distance of $5 \mu \mathrm{m}$ between each slice for a thickness of $150 \mu \mathrm{m}$. Both cell viability and cell area were manually counted and analyzed using ImageJ (National Institutes of Health, USA).

\subsection{Scaffold mechanics}

The mechanical properties were characterized by measuring the compressive modulus, which was assessed on a Zwick material testing machine (Zwick 1456, Ulm, Germany) with a $10 \mathrm{~N}$ load cell at room temperature. An unconfined uniaxial compression test was performed under displacement control, with a preload of $5 \mathrm{mN}$ and a strain rate of $1 \mathrm{~min}^{-1}$ until $60 \%$ maximal deformation of the construct was reached. Acellular scaffolds were tested after culture in osteogenic media for 1,7 and 42 days. The compressive modulus was calculated from the linear region of the stress-strain curve. Three scaffolds $(n=3)$ were measured per group, and the average value and standard deviation were obtained.

\subsection{Cell proliferation and ALP activity}

After culturing in osteogenic media for 7, 21 and 42 days, scaffolds were washed twice in PBS. Mini Beadbeater TM (Biospec, USA) was used for scaffold disintegration and cell lysate. The scaffolds were disintegrated in $0.45 \mathrm{ml}$ of $0.2 \%(\mathrm{v} / \mathrm{v}$ ) Triton X-100 and $5 \mathrm{mM}$ $\mathrm{MgCl}_{2}$ solution using two steel beads and the minibead beater. Each sample was processed three times at $25000 \mathrm{RPM}$ and $10 \mathrm{~s}$ for each time, and the sample was placed on ice between cycles for cooling. Cell proliferation was determined by measuring the DNA content obtained from the cell lysates. After $48 \mathrm{~h}$ incubation at room temperature at which time scaffolds had been disintegrated, the precipitate was separated by centrifugation at $3000 \mathrm{~g}$ for $10 \mathrm{~min}$ at room temperature. A Quant-iT TM PicoGreen assay (Life Technologies, Switzerland) of the supernatant fraction was performed according to the manufacturer's instructions. The DNA content was calculated with three samples in every group and averaged. ALP activity measurements were carried out directly after scaffolds had been disintegrated. Eighty microliters of the supernatant was mixed with $20 \mu \mathrm{L}$ of $0.75 \mathrm{M}$ 2-amino-2-methyl-1propanol (abcr GmbH, Germany) buffer and $100 \mu \mathrm{L} 100 \mathrm{mM}$ pnitrophenyl phosphate solution (Honeywell Fluka ${ }^{\mathrm{TM}}$, Hungary) and incubated for $2 \mathrm{~min}$ in a 96-well plate. Then, $0.2 \mathrm{M} \mathrm{NaOH}$ was added to stop the conversion of p-nitrophenyl phosphate to pnitrophenol. The absorbance values were measured at $405 \mathrm{~nm}$ and the p-nitrophenol amount was calculated using a standard curve included in the assay. The ALP activity was calculated by the pnitrophenol amount normalized to the DNA content in the same scaffold.

\subsection{Osteogenic-related gene expression}

Total RNA of the 3D cell-laden scaffolds was extracted using TRIzol Reagent (Invitrogen ${ }^{\mathrm{TM}}$, Thomas Fisher Scientific, USA), pellet pestles (Sigma-Aldrich, USA) and a RNeasy Micro Kit (Qiagen, Switzerland) according to the manufacturer's instructions. The RNA 
isolation method was performed as previously described [28]. RNA purity and concentration were quantified at $260 \mathrm{~nm}$ using a NanoDrop 2000 (Thermo Fisher Scientific, USA). Total RNA (410 ng) was reverse transcribed into cDNA using an iScript ${ }^{\mathrm{TM}}$ Synthesis Kit on a $1100^{\mathrm{TM}}$ thermal cycler (BIO-RAD, USA) according to the manufacturer's protocol. At the end of the procedure, cDNA samples were stored at $-20{ }^{\circ} \mathrm{C}$ until further analysis. Quantitative real-time PCR (RT-qPCR) was performed in a CFX96 ${ }^{\mathrm{TM}}$ real-time PCR system (BIO-RAD, USA) using a probe detection method. TaqMan Fast Universal PCR Master Mix (Thermo Fisher Scientific, USA) was used. Each gene was run in duplicate in a single plate, which included all the samples as well as controls. PCR conditions were as follows: denaturation $\left(95{ }^{\circ} \mathrm{C}\right.$ for $\left.20 \mathrm{~s}\right)$ followed by 43 amplification cycles $\left(95{ }^{\circ} \mathrm{C}\right.$ for $1 \mathrm{~s}, 60{ }^{\circ} \mathrm{C}$ for $20 \mathrm{~s}$ ). RT-qPCR was performed for six of the target genes (Alkaline phosphatase $(A L P L)$, Collagen type I alpha 2 chain (COL1A2), Bone gamma-carboxyglutamate protein $(B G L A P)$, Phosphate regulating endopeptidase homolog, X-linked (PHEX), Sclerostin (SOST), Dentin matrix acidic phosphoprotein 1 (DMP1)) and one housekeeping gene (Glyceraldehyde-3-phosphate dehydrogenase $(G A P D H))$. Details of the primers were provided in Table $S 1 . C_{t}$ values obtained for each sample were normalized to the housekeeping gene. Data were analyzed using the comparative $\mathrm{Ct}$ method $\left(2^{-\Delta \Delta \mathrm{Ct}}\right)$ and presented as a fold-change in gene expression of the GO groups versus the OGO group.

\subsection{In situ micro-CT monitoring of mineral formation in $3 D$ bioprinted cell-laden defect scaffolds}

SolidWorks software (Dassault Systemes S.A, Paris, France) was used to design a square model $(10 \mathrm{~mm} \times 10 \mathrm{~mm} \times 2.5 \mathrm{~mm})$ containing a single circle defect of $3 \mathrm{~mm}$ in diameter in the center and saved as a stereolithography file (STL). The scaffold defect model was converted into a G-Code file using Slic3r with $0.17 \mathrm{~mm}$ layer height, $0.76 \mathrm{~mm}$ pore size and $0.32 \mathrm{~mm}$ nozzle diameter. The bioprinting processes were the same as described above for printing the lattice-rod scaffolds. To keep the scaffolds stable such that they could not move during micro-CT scanning, scaffolds were directly bioprinted on a sterile $3 \mathrm{M}$ two-sided tape (Scotch, 3M, USA) that was adhered to the bioreactor platform, as previously described [28]. Modular bioreactors ( $\varnothing 36 \mathrm{~mm}$ ) made out of poly(ether imide) (PEI) were used to culture the 3D bioprinted cell-laden scaffolds. These bioreactors developed in-house enable culturing of the 3D bioprinted scaffolds under biocompatible and sterile conditions while also allowing non-invasive microCT imaging of the scaffolds in a fixed position. The bone bioreactor components contain the base, cap and platform, as depicted in Figure S1. During the cell culture, the bioreactor cap is half-opened to allow air exchange. During micro-CT scanning, the cap is fully closed to keep sterility. The scaffold defect model, 3D bioprinting method, $\mathrm{Ca}^{2+}$ crosslinking, bioreactor assembly and in situ microCT scanning and micro-CT evaluation processes are shown in Fig. 6.

In situ micro-CT images of all defect scaffolds cultured in bone bioreactors with $5 \mathrm{ml}$ osteogenic media were captured at 7, 14, 21, 28,35 and 42 days to monitor mineral formation, as described previously [30,31]. All bioreactors were scanned using a micro-CT 40 (SCANCO Medical AG, Brüttisellen, Switzerland) at a voxel resolution of $36 \mu \mathrm{m}$. The energy was set to $45 \mathrm{kVp}$, the intensity was $177 \mu \mathrm{A}$, the integration time was $200 \mathrm{~ms}$, and two-fold frame averaging was chosen. The reconstructed images were Gaussian filtered with a filter width of 1.2 and support of 1 to suppress noise. Mineralized tissue was segmented by thresholding at a grayscale value of 145 (corresponding to a mineral density of $83.44 \mathrm{mg} \mathrm{HA} \mathrm{cm}^{-3}$ ) [28]. Unconnected particles smaller than 50 voxels were removed using component labeling. The resulting 3D volume was evaluated morphometrically for mineral volume $\left(\mathrm{mm}^{3}\right)$ and mineral change $\left(\mathrm{mm}^{3} /\right.$ day $)(($ mineral change $=$ mineral volume day $\mathrm{m}$ - mineral volume day $n) /(m-n))$, as described previously [30-32].

\subsection{Histology staining}

After 42 days of culture in osteogenic media, the scaffolds were washed twice with PBS and fixed in $4 \%$ formaldehyde in $10 \mathrm{mM}$ $\mathrm{CaCl}_{2}$ and $0.15 \mathrm{M} \mathrm{NaCl}$ solution for $2 \mathrm{~h}$. Then, the samples were placed in a $30 \%$ sucrose solution with $10 \mathrm{mM} \mathrm{CaCl}$, solution for $16 \mathrm{~h}$ at room temperature. After that, the samples were cryoembedded using optimum cutting temperature compound (OCT, VWR) and snap-frozen on dry ice. The samples were sectioned using Kawamoto's cryofilm type 2C (SECTION-LAB Co. Ltd., Japan) to $7 \mu \mathrm{m}$ thickness using a cryotome (CryoStar NX70, Thermo Scientific) according to the Kawamoto protocol [33]. Before staining, the sections were fixed on microscope slides using $1 \%$ chitosan adhesive. For this purpose, two drops of chitosan solution were deposited on the slide, and the sections were placed on the slide and kept in a running fume hood to allow the chitosan to dry [33]. Alizarin red S staining was performed to visualize mineralized $\mathrm{ECM}$, and hematoxylin and eosin (H\&E) staining was performed to visualize cell nuclei and dendrites. The slides were imaged on an automated slide scanner (Pannoramic 250 Flash II, 3Dhistech, Hungary) using the brightfield channel with a magnification of $20 \mathrm{x}$. Alizarin red $S$ staining to identify the mineral location and was compared with the micro-CT slice, as shown in our previous work [28].

\subsection{Statistical analysis}

GraphPad Prism 8 (GraphPad, California, USA) was used to perform the statistical analysis of the obtained data. Groups were compared at one timepoint using one-way ANOVA together with pairwise comparisons, followed by Tukey corrections. The 0GO, $0.5 \mathrm{GO}, 1 \mathrm{GO}$ and $2 \mathrm{GO}$ groups were compared at different timepoints using two-way ANOVA together with Tukey's multiple comparisons test. * $\mathrm{P}<0.05$ was considered statistically significant, and a b c d represent significant differences $(\mathrm{P}<0.05)$ compared with the $0 \mathrm{GO}, 0.5 \mathrm{GO}, 1 \mathrm{GO}$ and $2 \mathrm{GO}$ groups, respectively, at the same time point. Data are shown as mean \pm standard deviation $(n=4)$.

\section{Results and discussion}

\subsection{GO characterization, bioink preparation}

Commercially available GO was produced through oxidation/exfoliation of graphite powder via the modified Hummer's method. GO nanoflakes displayed a lateral size of $>15 \mu \mathrm{m}$ and a thickness of $0.8-1.2 \mathrm{~nm}$, according to the manufacturer's information. The morphology of GO was characterized by TEM analysis (Fig. 1A), which showed that the GO was single-layer materials. The exfoliated GO nanosheets were readily dispersed in deionized water with ultrasonic treatment and formed a suspension that was stable for several months with no precipitation. Photograph and optical microscopy analysis (Fig. 1B C) showed that the $5 \mathrm{mg} / \mathrm{ml}$ GO dispersion in water solution is a homogeneous and stable suspension without aggregation. As GO flasks are brown, the GO flask conjugation to alginate/gelatin chains changed the hydrogel color from white to brown to black according to the GO concentration, as shown in the photograph (Fig. 1D). To confirm the dispersion of GOs within the hydrogel solutions, optical microscopy analysis of the GO/alginate/gelatin composite solution was performed. No evidence of aggregation was observed, and a homogeneous distribution of GO flakes throughout the volume was revealed. When the GO concentration was increased from 0.5 to $2 \mathrm{mg} / \mathrm{ml}$ in the 
composite hydrogels, more GO flakes could be observed under the optical microscopy images (Fig. 1E-H). Our result is similar to previous findings reported by Guo and Scaglione et al [24,34], who demonstrated that the negative ions in both alginate and GO allow the formation of a homogeneous and stable solution.

\subsection{Rheological properties}

The rheological properties of the hydrogels with varied GO contents were measured to determine the shear behavior and shear recovery, two of the most important predictors of bioink printability. In our study, we observed that viscosities tend to increase with the GO content in the alginate/gelatin bioink. For example, the viscosities of the inks at a shear rate of $1 \mathrm{~S}^{-1}$ were 257, 596, 970 and $2131 \mathrm{mPa}$.s for $0 \mathrm{GO}, 0.5 \mathrm{GO}, 1 \mathrm{GO}$ and 2GO, respectively. Meanwhile, all of the bioink compositions showed shear-thinning behavior as the viscosities decreased with increases in shear rate, while the higher GO content group showed better shear-thinning properties (Fig. 1I). As a consequence of shear-thinning, the coiled polymer chains align and disentangle at higher shear rates, requiring less extrusion force to deposit the bioink, which is beneficial for cell survival in 3D extrusion-based bioprinting. Shear recovery relates to the ink's resistance to flow after printing, which ensures high fidelity of the printed structure. The shear recovery curves (Fig. 1J) illustrate that incorporating GO into the alginate/gelatin composite hydrogel increases shear recovery. Shear recovery after the first shear sequence was $79.55 \%$ in $0.5 \mathrm{GO}, 97.09 \%$ in $1 \mathrm{GO}$ and $51.08 \%$ in $2 \mathrm{GO}$ of the original storage modulus. At the same time, the bioink without GO recovered to only $37.39 \%$. Previous studies also indicated that the GO incorporation of alginate inks significantly increased viscosity, shear-thinning properties, and shear recovery as GO interacts with alginate chains [25,35]. Furthermore, because of the thermosensitive properties of gelatin, forming a stable 3D bioprinted $\mathrm{GO} /$ alginate/gelatin construct required decreasing the temperature from $37^{\circ} \mathrm{C}$ to $10{ }^{\circ} \mathrm{C}$. Representative curves of the viscoelastic moduli of the different hydrogel groups are shown in Fig. $1 \mathrm{~K}$. The storage and loss moduli of the GO/alginate/gelatin hydrogel significantly increased during the gelation process, indicating an increase in viscosity and bioink stability. The influence of the GO concentration on the gelation point is shown in Fig. $1 \mathrm{~L}$. The gelation points for the $0 \mathrm{GO}, 0.5 \mathrm{GO}, 1 \mathrm{GO}$ and $2 \mathrm{GO}$ groups were $21.6 \pm 0.3{ }^{\circ} \mathrm{C}, 21.5 \pm 0.3{ }^{\circ} \mathrm{C}, 21.6 \pm 0.2{ }^{\circ} \mathrm{C}$ and $21.6 \pm 0.1{ }^{\circ} \mathrm{C}$, respectively. There was no statistically significant difference in the gelation point between hydrogels with different GO concentrations. Ma et al. [36] showed that the gelation point is mostly related to the gelatin concentration in gelatin-based bioink composition. To study the influence of temperature change during printing process on bioink printability, Figure S2 was showed that all those 3D bioprinted acellular 0GO scaffold images were similar and the scaffold parameter was not different. The results confirmed that the small temperature change during printing does not influence printing performance and scaffold morphology.

\subsection{Scaffold structure}

Hydrogels are well known for their swelling behavior, which is an essential consideration in predicting the functioning of the printed geometry and achieving an accurate spatial distribution of material and cells [37]. We evaluated the morphology of 3D bioprinted acellular (Fig. 2) and cell-laden (Fig. 3) GO composite scaffolds. Light microscopy images showed that 3D acellular and cell-laden GO scaffolds were successfully bioprinted with regular and interconnected macroporous structures. Fig. 2 shows that acellular scaffolds had different overall shrinkage compared with the scaffold model $(10 \times 10 \mathrm{~mm})$ depending on the GO concentration. Increasing the GO concentration showed higher scaffold area fidelity with less scaffold dimension reduction. As shown in Fig. 2E at day 7, the acellular scaffold overall area of OGO was $65.36 \pm 3.87 \mathrm{~mm}^{2}$, which was significantly lower than $89.60 \pm 6.31 \mathrm{~mm}^{2}, 92.39 \pm 6.68 \mathrm{~mm}^{2}, 96.08 \pm 2.75 \mathrm{~mm}^{2}$ obtained for $0.5 \mathrm{GO}, 1 \mathrm{GO}$ and $2 \mathrm{GO}$, respectively. The pore size and pore area of $0 \mathrm{GO}$ were $0.58 \pm 0.02 \mathrm{~mm}$ and $0.28 \pm 0.01 \mathrm{~mm}^{2}$, respectively, which were not significantly different from those of the GO groups (Fig. 2 F G). However, the filament diameters of $0.5 \mathrm{GO}, 1 \mathrm{GO}$ and $2 \mathrm{GO}$ were $0.33 \pm 0.04,0.32 \pm 0.02$, and $0.36 \pm 0.01 \mathrm{~mm}$, respectively, which were significantly higher than $0.23 \pm 0.02 \mathrm{~mm}$ for $0 \mathrm{GO}$ at day 7 (Fig. $2 \mathrm{H}$ ).

Similar changes in scaffold morphology as observed in the acellular scaffolds were found in the 3D bioprinted cell-laden scaffolds after culture in the osteogenic cell culture media for 1 day and 7 days (Fig. 3A). 3D cell-laden scaffolds with higher GO content improved the scaffold morphology with less shrinkage over 7 days. However, after long-term culture in osteogenic media for 42 days, the 2GO group exhibited prominent swelling, and no significant differences were detected among the 0GO, 0.5GO and $1 \mathrm{GO}$ groups from day 7 to day 42 . Pore size, filament diameter and overall scaffold area of the $2 \mathrm{GO}$ group significantly differed between day 1 and 42 ; these parameters in the $2 \mathrm{GO}$ group also significantly differed compared with those of the 0GO, 0.5GO and $1 \mathrm{GO}$ groups at day 42 (Fig. 3 B-D). Over 42 days cultured in the osteogenic media, the OGO scaffolds were shrinkage and had the lower scaffold overall area and filament diameter compared to 0.5GO, $1 \mathrm{GO}$ and 2GO. All those scaffolds were bioprinted using the same underlying scaffold model $(10 \times 10 \times 2.5 \mathrm{~mm})$, which means that in the ideal case the scaffold overall area would be $10 \times 10 \mathrm{~mm}$. Nevertheless, the 0GO group exhibited shrinkage when culturing in the incubator, especially in the first week, and therefore the 0GO group has the lowest scaffold overall area at day 7 and day 42 . When incorporating GO in the alginate/gelatin ink system, GO scaffolds kept their scaffold overall area closer to the prescribed model exhibiting a higher scaffold overall area as compared to the 0GO group. The shrinkage in the 0GO group is the reason why the 0GO group appears denser than the GO groups. Nevertheless, as filament diameter was significantly reduced in the $0 \mathrm{GO}$ group and pore size was not affected, the overall density is reduced in these scaffolds albeit the fact that they shrunk. The best candidate for maintaining scaffold morphology compared with the scaffold design model was the scaffold of the $1 \mathrm{GO}$ group.

The shrinkage behavior of OGO was similar to that observed in our previously published study when the scaffold was cultured in cell culture media [10]. James et al. [38] and Ma et al. [36] reported that ionically crosslinked alginate gel will lose its stability due to the loss of crosslinking calcium ions when in the presence of calcium chelators (e.g., phosphates), monovalent ions (e.g., $\mathrm{K}^{+}$, $\mathrm{Na}^{+}$, etc.), and non-crosslinking divalent ions (e.g., $\mathrm{Mg}^{2+}$ ). However, alginate gels could remain stable in cell culture media because some calcium ions in the media counteract the deprivation effects $[39,40]$. Incorporating GO into the 3D bioprinted alginate/gelatin scaffolds could help maintain better scaffold morphology when cultured in the cell culture media in the short term. The existence of hydrogen bonding and high interfacial adhesion between GO and alginate chains probably contribute to better scaffold stability. Choe et al. [25] indicated that 3\% alginate scaffolds were swelling due to the loss of $\mathrm{Ca}^{2+}$, while the addition of $\mathrm{GO}$ to alginate can promote structural stability of alginate-based scaffolds with reduced swelling during 5 days of incubation. The incorporation of GO into low-density alginate/gelatin $(0.8 \% / 4.1 \%)$ ink seems to keep better scaffold fidelity than high-density inks. The overall size of $0.5 \mathrm{GO}$ and $1 \mathrm{GO}$ scaffolds were around $85 \%$ of the original size after printing at day 7 and $95 \%$ at day 42 , while $3 \% \mathrm{alg} / \mathrm{GO}$ groups were around $130 \%$ at day 5 in Choe's results. Meanwhile, some researchers have reported that GO has extraor- 

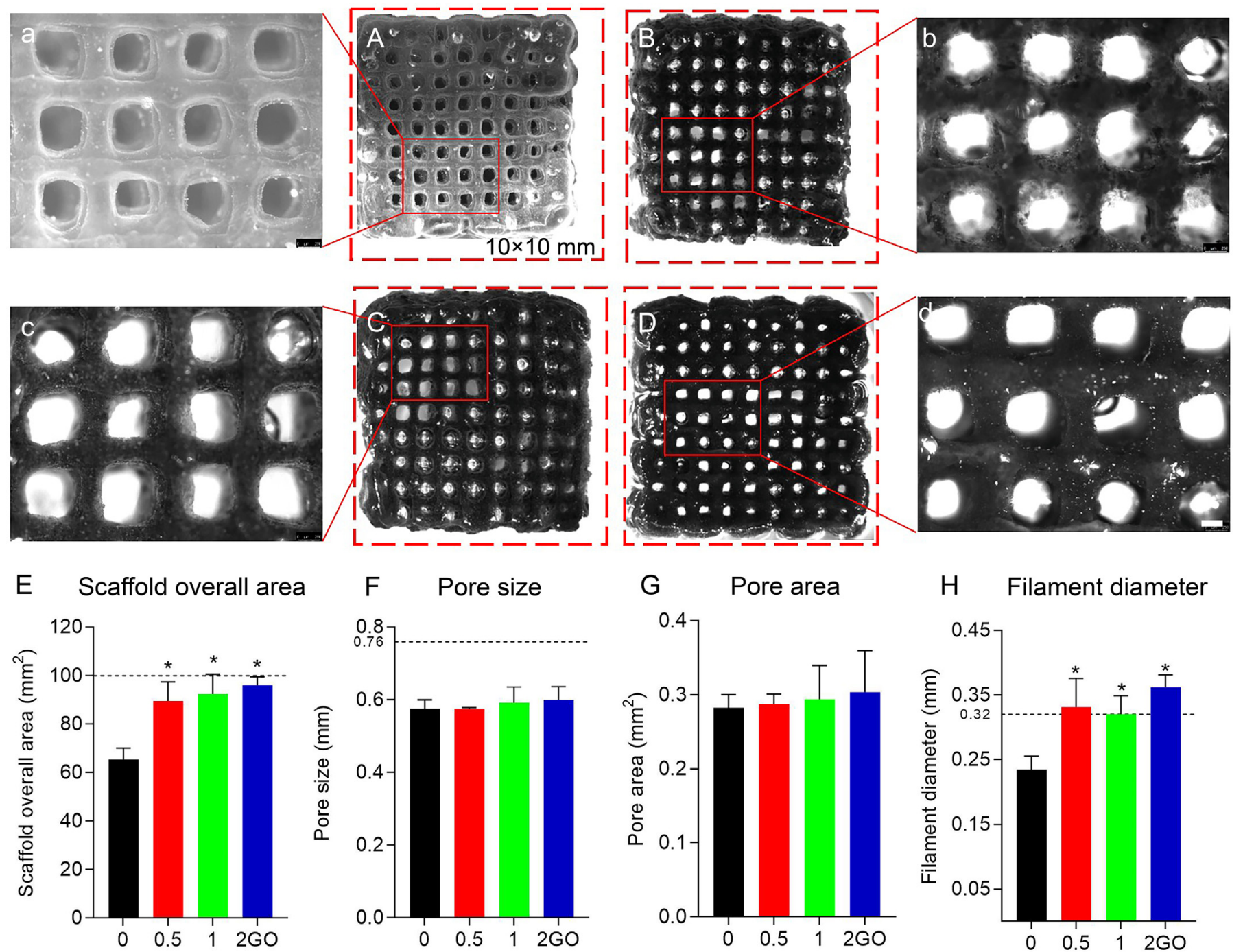

\section{H Filament diameter}

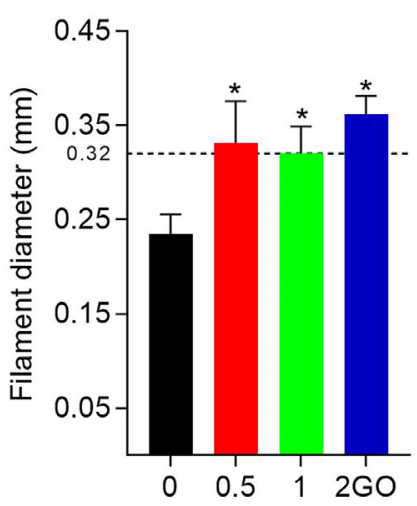

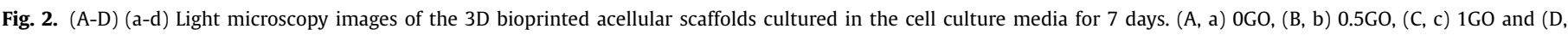

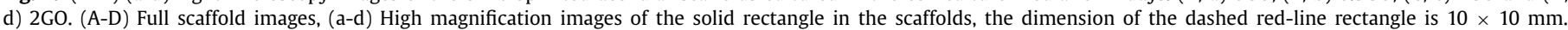

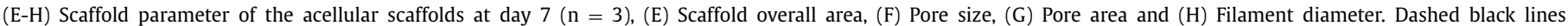
represent the values of the designed scaffold model. ${ }^{*} \mathrm{P}<0.05$ was compared to the $0 \mathrm{GO}$ group.

dinary absorption capacity for positive ions [41], proteins [42], and small molecule drugs $[43,44]$ via electrostatic interactions and $\pi-\pi$ stacking. During 42 days of culturing, the electrostatic interactions between $\mathrm{GO}$ and $\mathrm{Ca}^{2+}$ may increase the loss of calcium ions in the crosslinked alginate chains and decrease the stability of alginate scaffolds, especially in the $2 \mathrm{GO}$ group. A higher GO concentration resulted in the absorption of more hydrophilic proteins and water molecules, which also contributes to the swelling behavior in the 2GO group.

\subsection{Scaffold mechanics}

To investigate the effect of incorporating GO on the mechanical properties, unconfined compression tests were performed on 3D bioprinted cell-laden GO scaffolds cultured in osteogenic media for 1,7 and 42 days. Fig. 3E shows the compressive moduli of 3D bioprinted cell-laden scaffolds with a range of GO concentrations $(0,0.5,1,2 \mathrm{mg} / \mathrm{ml})$. In agreement with other studies using various hydrogels [25,45], the incorporation of GO improved the mechanical properties of the 3D bioprinted cell-laden scaffolds on day 1 . The compressive moduli of the $1 \mathrm{GO}$ and $2 \mathrm{GO}$ scaffolds were $1.58 \pm 0.28 \mathrm{kPa}$ and $1.63 \pm 0.29 \mathrm{kPa}$, respectively, which were significantly higher than that of $0 \mathrm{GO}(0.69 \pm 0.24 \mathrm{kPa})$ on day 1 . The increase in compressive moduli is attributed to the good compatibility between the alginate matrix and the GO owing to the presence of strong interactions (e.g., hydrogen bonding) between the alginate chains and the GO nanosheets [34]. After 7 days of cell culture, a slight decrease in the compressive modulus was observed for the $0.5 \mathrm{GO}, 1 \mathrm{GO}$, and $2 \mathrm{GO}$ groups. There were no statistically significant differences between the two groups on day 7. This result is possibly due to the water uptake ability of GO, decreasing the stiffness of the matrixes. Interestingly, a dramatic enhancement of the compressive moduli was observed from day 7 to day 42 of culture in osteogenic media in all groups. There were significant differences within the same group between day 42 and day 1, between day 42 and day 7 . The compressive modulus on day 42 was 12 times higher for the $0 \mathrm{GO}$ and $0.5 \mathrm{GO}$ scaffolds, 7.3 times higher for the $1 \mathrm{GO}$ scaffolds and 4.3 times higher for the 2GO scaffolds than on day 7. Marrella et al. [24] also demonstrated that stiffness of GO/alginate functionalized hydrogels was increased dramatically from one week to four weeks of cell culture. We believe that cell spreading and extracellular matrix mineraliza- 

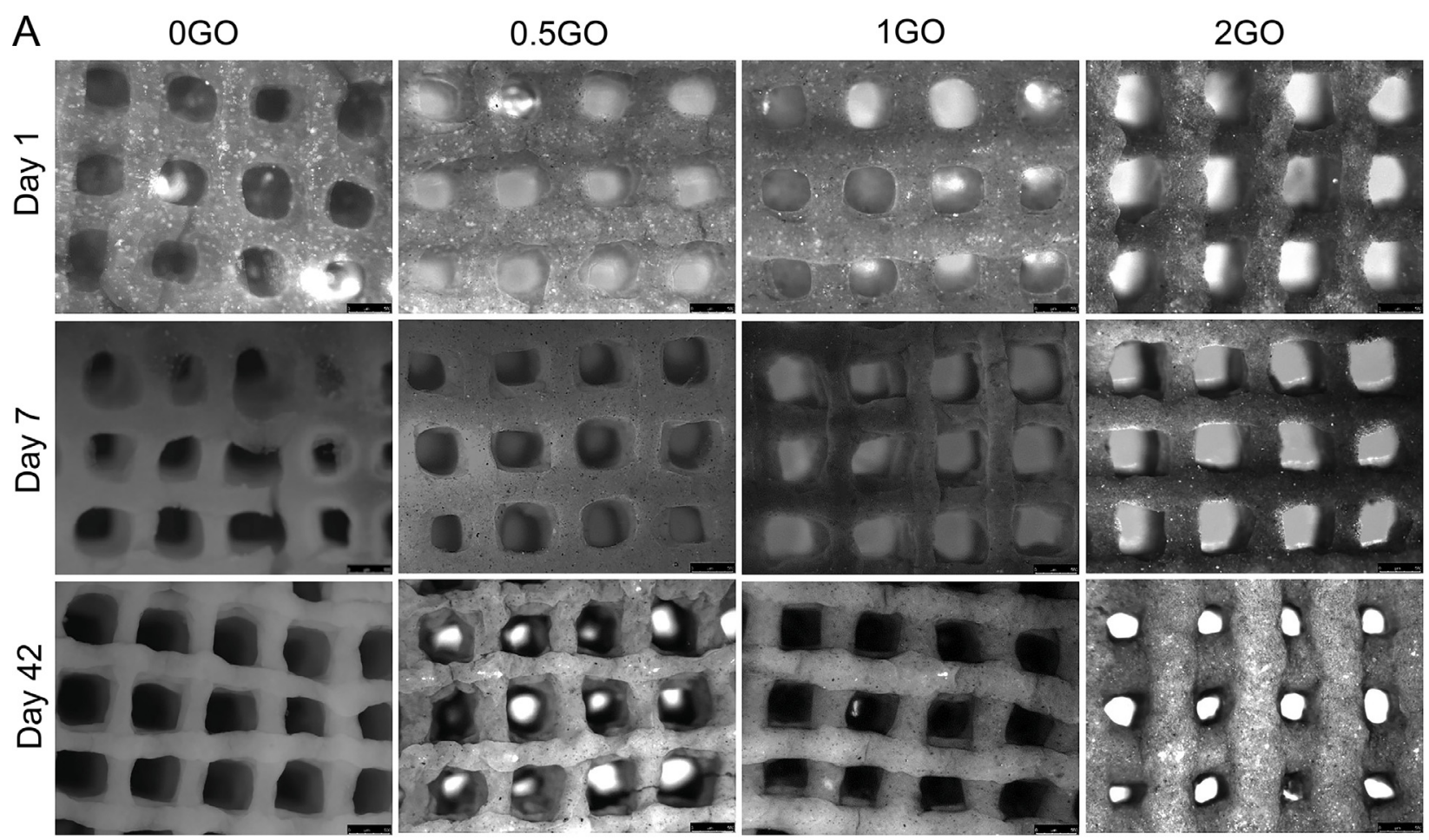

\section{B}

Scaffold overall area

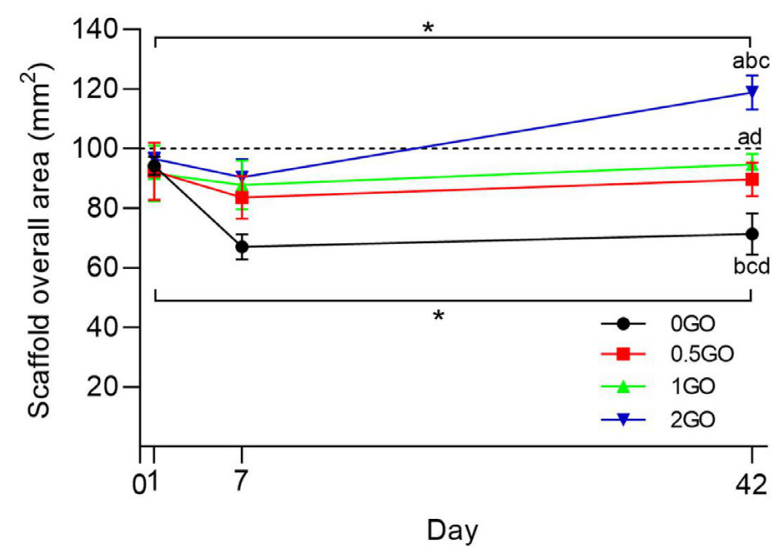

D

Filament diameter
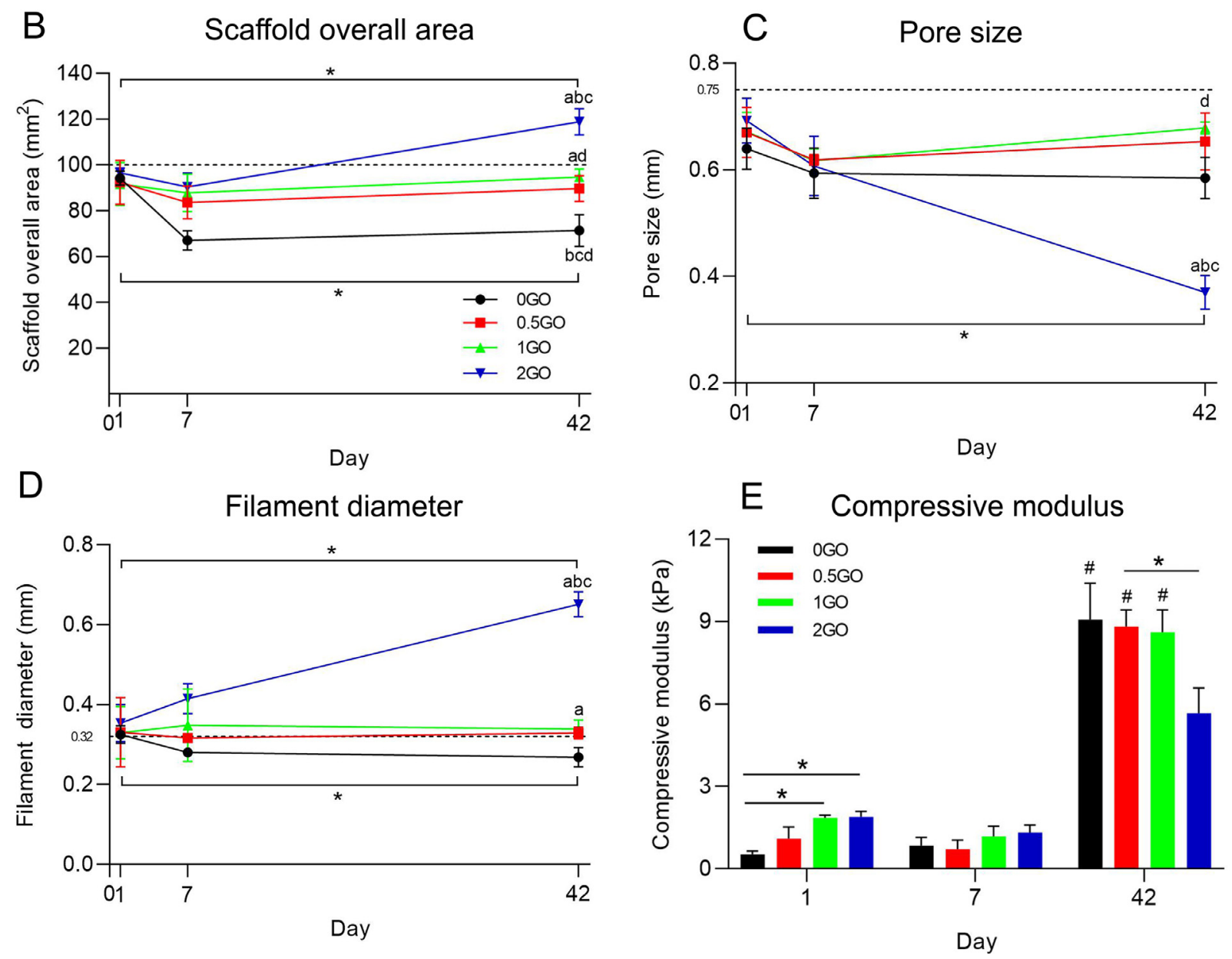

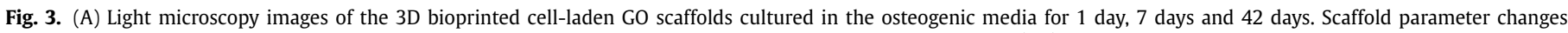

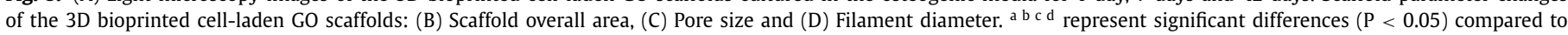

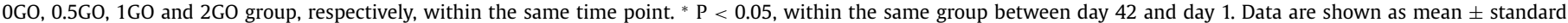

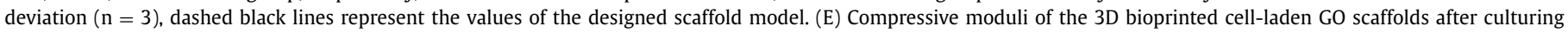
in the osteogenic media for 1 day, 7 days and 42 days. ${ }^{*} \mathrm{P}<0.05$, and $\# \mathrm{P}<0.05$ between day 42 and day 1 , between day 42 and day 7 . 
tion was mostly responsible for the enhanced compressive modulus in later time points. The swelling behavior with good water uptake ability of $2 \mathrm{GO}$ decreases the compressive moduli of these scaffolds. Compressive stiffness, as well as permeability, is highly correlated with water content: as the water content increases, the material becomes less stiff and more permeable $[46,47]$.

\subsection{Cell viability and cell area}

To investigate whether the cell-material interactions are compromised by the presence of GO in the scaffolds, the viability of hMSCs after short- and long-term culture was analyzed. The cytotoxic effects of GO were evaluated by comparing the cell viability results obtained between $0 \mathrm{GO}$ and the different $\mathrm{GO}$ concentrations. Fig. 4A shows representative images depicting cell viability in the 3D bioprinted cell-laden GO scaffolds on day 1, day 7, and day 42 of culture. The predominant green fluorescence evidences the high population of live cells in all groups. Comparing to the cell viability images in day 1, 7 and 42, a decrease of total cell number in day 42 was shown in Figure S3. We did not observe more dead cells in cell viability images in day 42 and some dead cells were probably degraded. Fig. 4B shows the quantitative analysis of cell viability in 3D bioprinted cell-laden GO scaffolds on day 1, day 7, and day 42. GO decreased cell death by increasing the concentration of GO, with significant differences detected at $2 \mathrm{GO}$ compared with 0GO on day 1 and day 7 .

Furthermore, all groups supported cell spreading and cell-cell interactions after 42 days of culture. However, the GO concentration influenced the cell spreading capabilities (Fig. 4A and 4C). The cells in the 0GO scaffolds were homogeneously dispersed and showed a spindle-shaped morphology, whereas those in GO scaffolds were larger and more outspread (Fig. 4A). Fig. 4C shows the influence of GO incorporation on the projected cell area in 3D bioprinted cell-laden scaffolds. The results showed that there were no significant differences within the same group between day 7 and day 1 , but significant differences were found within the same group between day 42 and day 1 and between day 42 and day 7 . The results indicate that the projected cell area was significantly increased after culture in osteogenic media for 42 days. Meanwhile, the cell area increased with higher GO concentration, and the projected cell area of the GO groups (0.5GO, $1 \mathrm{GO}$ and 2GO) was significantly higher than that of the OGO group on day 7 and day 42 . A trend towards a higher projected cell area was observed with increasing GO concentrations; however, no significant difference were found within GO groups. Some researchers have demonstrated that the extraordinary absorption behavior of GO promotes the deposition of nutrition components (such as FBS) on the scaffold surface and is favorable for cell survival and spreading [48]. Our results were similar to the findings of Lee et al. [22], who studied the effect of graphene, GO, and polydimethylsiloxane (PDMS) on the 2D differentiation of hMSCs. They found that the cells cultured on graphene and GO exhibited cellular protrusions, which were distinctively different from those cultured on PDMS. The two higher GO concentrations (1GO and 2GO) favored earlier cell spreading at day 7 compared with $0.5 \mathrm{GO}$ and 0GO. In addition, higher cell aggregations were visible in the GO groups after 42 days of culture. Su et al. [27] showed that cells that were encapsulated in GO-incorporated hydrogels (GO concentration of $2 \mathrm{mg} / \mathrm{ml}$ ) were more metabolically active than those in pure gelatin methacrylate (GelMA) hydrogels.

\subsection{Cell proliferation}

Cell proliferation in 3D bioprinted cell-laden GO composite scaffolds was investigated at day 7, 21 and 42 after culturing in osteogenic media. GO influenced the DNA content after 7 and 42 days of culture. Fig. 5A shows that DNA content was decreased in all groups when cultured in the osteogenic media, which was consistent to a marked drop of total cell number in cell viability images from day 7 to day 42 (Fig. 4A and Fig. S3). There are several reasons that may contribute to the DNA decrease over time. Some encapsulated cells may have detached form the scaffolds because of the movement of media within the well plate. Previous studies have also reported increased cell death with increased osteogenic differentiation [49,50]. The extraction of cells may be hampered due to ECM mineralization after 42 days of culture in osteogenic media. However, the DNA content of the $1 \mathrm{GO}$ and 2GO groups was significantly higher than that of 0GO group on day 7 and day 42. This result is consistent with the fact that GO incorporation increases cell proliferation and may be related to the strong adsorption capacity of GO by $\pi-\pi$ stacking and electrostatic interactions $[22,23,51]$. This adsorptive performance can be considered favorable to FBS adsorption and subsequent cell proliferation. Previous studies [52,53] have also reported that the incorporation of carbon-based nanomaterials, such as carbon nanotubes, into ECMderived substrates support enhanced cellular adhesion and proliferation due to the strong affinity between nanomaterials and ECM proteins. No significant difference was detected between the 0GO and GO groups on day 21. Due to the low cytotoxicity of GO, the incorporation of GO has also been shown to slightly inhibit the proliferation of hMSCs [54]. Several factors such as concentration, size and shape can influence the cytotoxicity of GO. The generation of reactive oxygen species (ROS) is known as a common toxicity mechanism of GO and there is a correlation between cell death and ROS generation in or near cells [55]. Therefore, the absorption of serum proteins and low cytotoxicity of GO may synergistically contribute to the similar DNA content at day 21 in 0GO and GO groups.

\subsection{ALP activity and osteogenic-related gene expression}

Alkaline phosphatase (ALP) contributes to the production of ECM for deposition before the initiation of mineralization [56]. In contrast to the results for DNA content, the p-nitrophenol amount (Figure S4) and ALP activity (Fig. 5B) increased overtime in all groups. When comparing the influence of GO, a significantly higher in the p-nitrophenol amount and ALP activity was observed for the $1 \mathrm{GO}$ and $2 \mathrm{GO}$ after 21 days compared to $0 \mathrm{GO}$, suggesting that GO induces osteoblastic differentiation. After 42 days of culture, no differences in the ALP activities were observed, due to the decrease of DNA content in 0GO, although the p-nitrophenol amount in GO groups was significantly higher than 0GO. Differences in the ALP activity at day 21 and day 42 could be explained by the inverse correlation in the DNA content and ALP activities overtime, which was more pronounced for the OGO group. The effect of GO on the osteogenic differentiation of hMSCs towards osteoblasts and the osteocyte lineage was further evaluated after culturing in osteogenic media for 42 days (Fig. 5C). Osteoblasts and osteocytes are characterized by a sequence of gene expression. The relative expression of early- (COL1A2), middle- (ALPL), and late- (BGLAP) stage osteoblast-related genes and osteocyte-related genes (PHEX, DMP1, SOST) are shown in Fig. 5C. ALPL and BGLAP gene expression was significantly increased in the $0.5 \mathrm{GO}$ and $1 \mathrm{GO}$ groups compared with the OGO group. PHEX is a gene expressed at the early stage of osteocytes and is involved in regulating skeletal mineralization. In line with the results observed for ALPL and BGLAP, PHEX gene expression was significantly upregulated in the $0.5 \mathrm{GO}$ group compared with the 0GO group and in the $1 \mathrm{GO}$ group compared with the $0 \mathrm{GO}$ and $0.5 \mathrm{GO}$ groups. No differences in COL1A2 and SOST were observed compared with the 0GO group. Although not statistically relevant, the DMP1 gene was only upregulated in the 0GO and $0.5 \mathrm{GO}$ groups. Interestingly, $2 \mathrm{GO}$ did not upregulate the ex- 

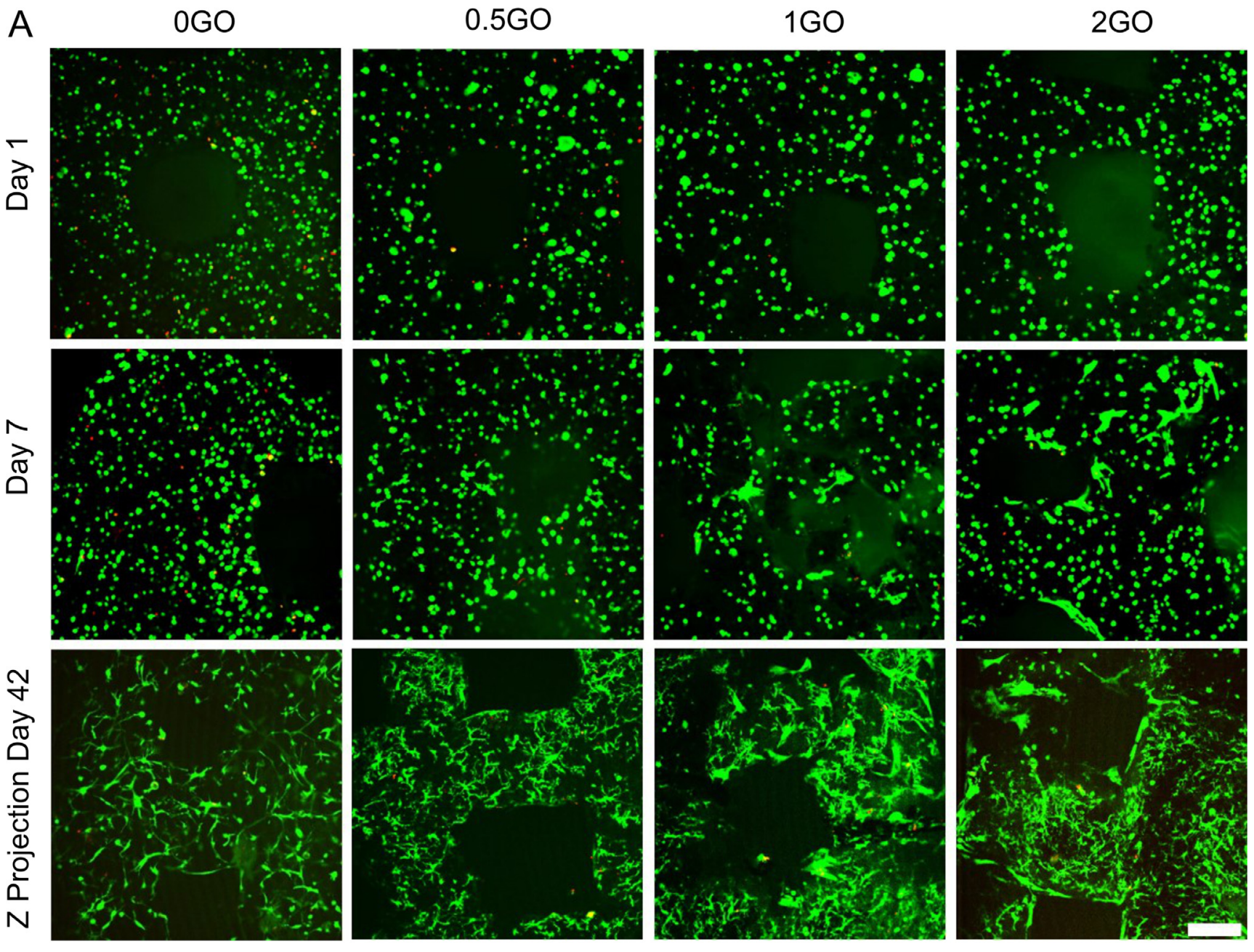

B

Cell viability

C

Projected area per cell
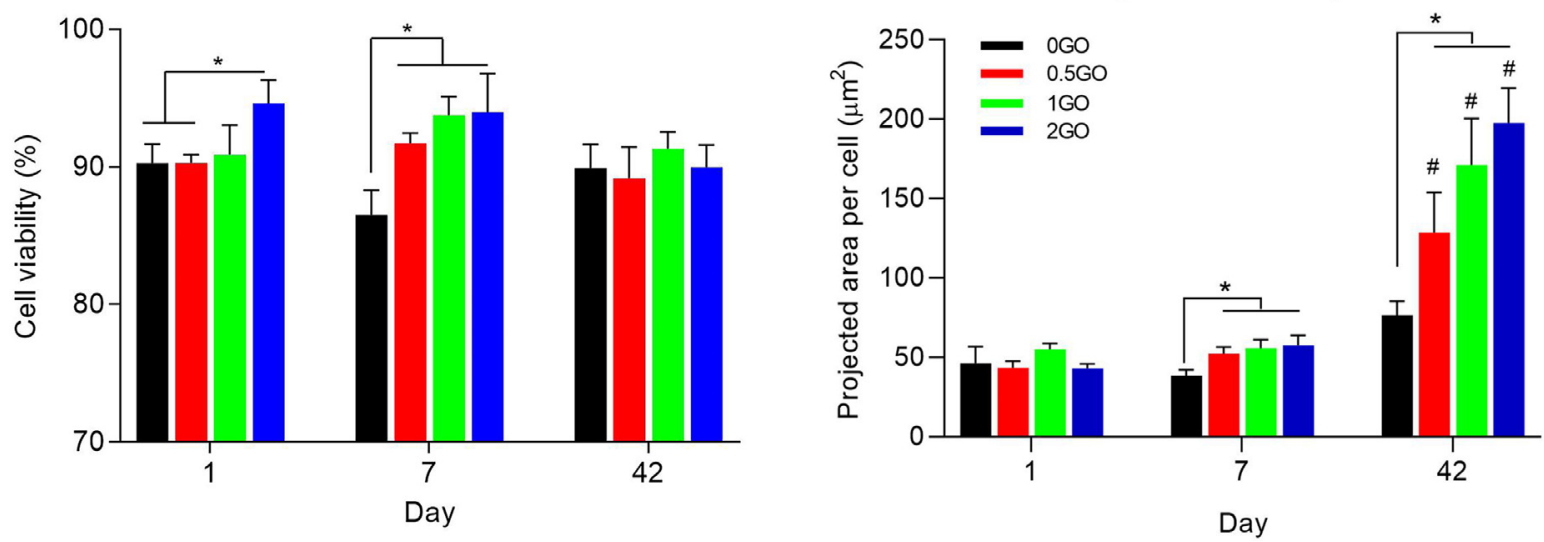

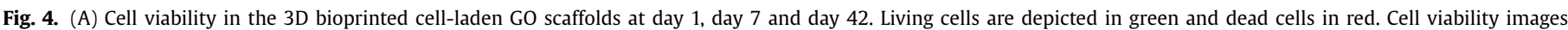

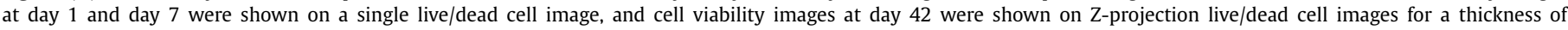

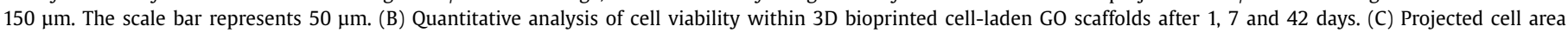

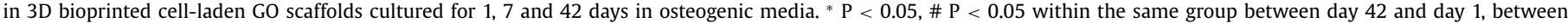
day 42 and day 7 . Data are shown as mean \pm standard deviation $(n=3)$.

pression in any of the genes evaluated compared with 0GO. During the first steps of osteogenic differentiation, MSCs proliferate and commit to actively proliferating pre-osteoblasts. They further mature into non-proliferating osteoblasts involved in initial matrix secretion, maturation, and mineralization. Cells start expressing osteogenic markers, such as ALP and osteocalcin. Once ECM is formed, osteoblasts have three possible fates: 1) die by apoptosis, 2) become osteocytes embedded in the mineralized bone matrix, or 3) become inactive quiescent bone lining cells [57]. Here we suggest that after promoting early cell proliferation in GO groups, more cells were developed an osteoblastic-osteocytic genotype as revealed by the upregulation of ALPL, BGLAP and PHEX 
A

A

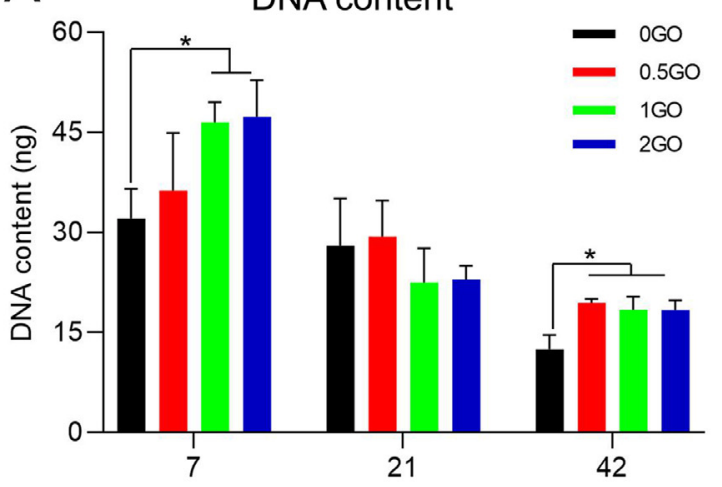

Day

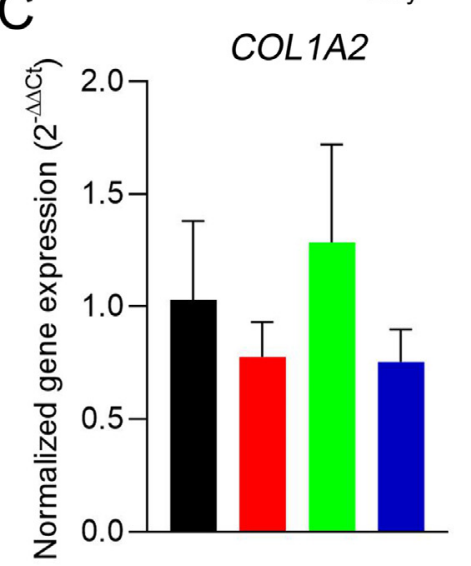

PHEX

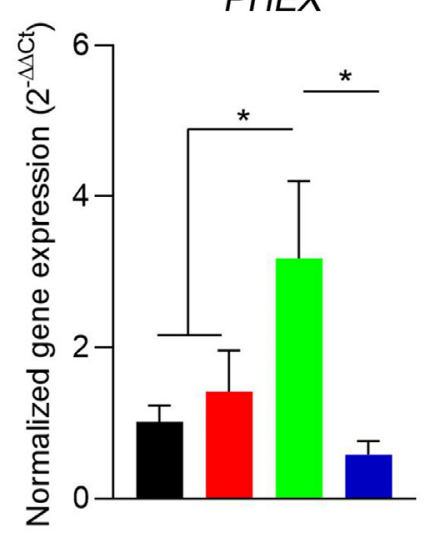

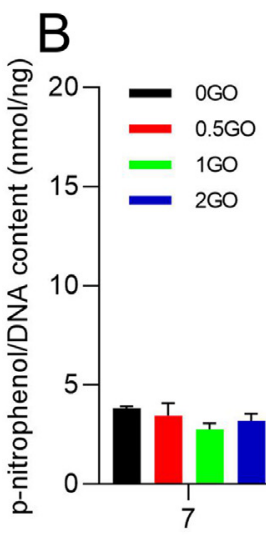

ALP activity

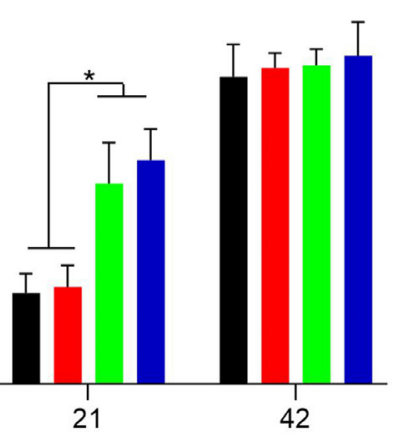

Day
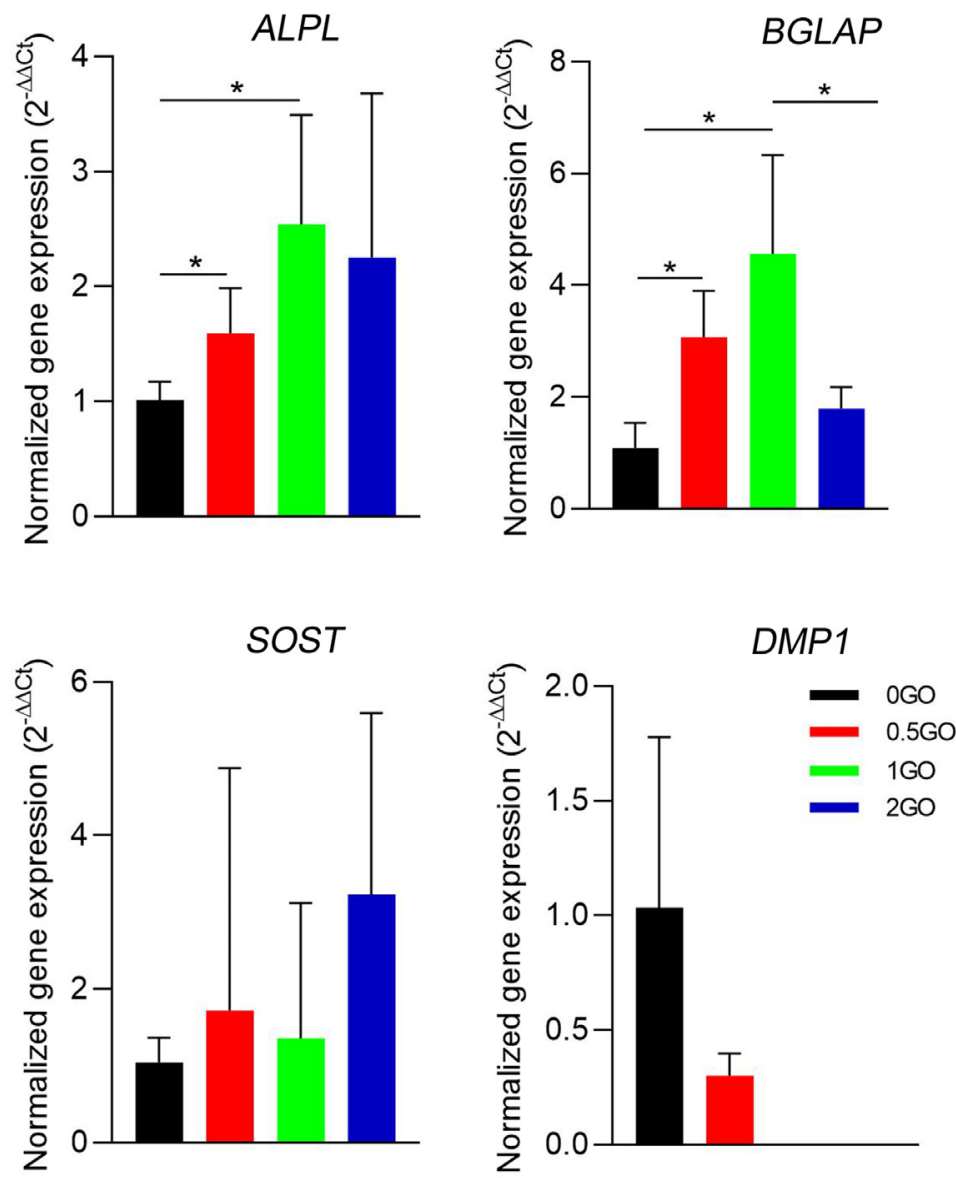

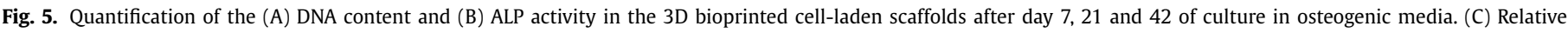

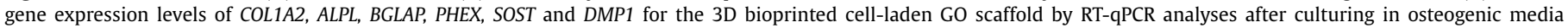
for 42 days. ${ }^{*} \mathrm{P}<0.05$, data are shown as mean \pm standard deviation $(\mathrm{n}=3)$.

on day 42 than 0GO. Overall, our results indicate that appropriate GO incorporation can promote hMSC differentiation into mature osteoblasts and early osteocyte phenotypes, and the optimal group was $1 \mathrm{GO}$. Likewise, several previous studies have reported that graphene or GO can promote osteogenesis of MSCs [22]. Although exact mechanisms were not elaborated, this may be explained by the higher conductivity of GO [58] and its unique structure with surface oxygenated groups [22,59] compared with alginate or gelatin. It has been shown that the poor conductivity of GO can also have positive effects on cell proliferation and differentiation [60]. Surface oxygenated groups, such as $\mathrm{OH}^{-}$and $\mathrm{COO}^{-}$, endow GO with the ability to adsorb specific proteins (present in FBS) [48] and low-molecular-weight chemicals, such as osteogenic inducers (dexamethasone and $\beta$-glycerophosphate) [22]. Therefore, it is reasonable to speculate that the improved osteogenic differentiation of hMSCs by GO incorporation may be directly related to the specific bioactive groups and extraordinary absorption capacity of GO [61]. However, when the concentration of GO reached $2 \mathrm{mg} / \mathrm{ml}$, it exerted adverse effects on osteogenic cell differentiation. The results are in line with the finding that abundant GO induces oxidative stress in cells and generates ROS that inhibit cell differentiation [62]. 


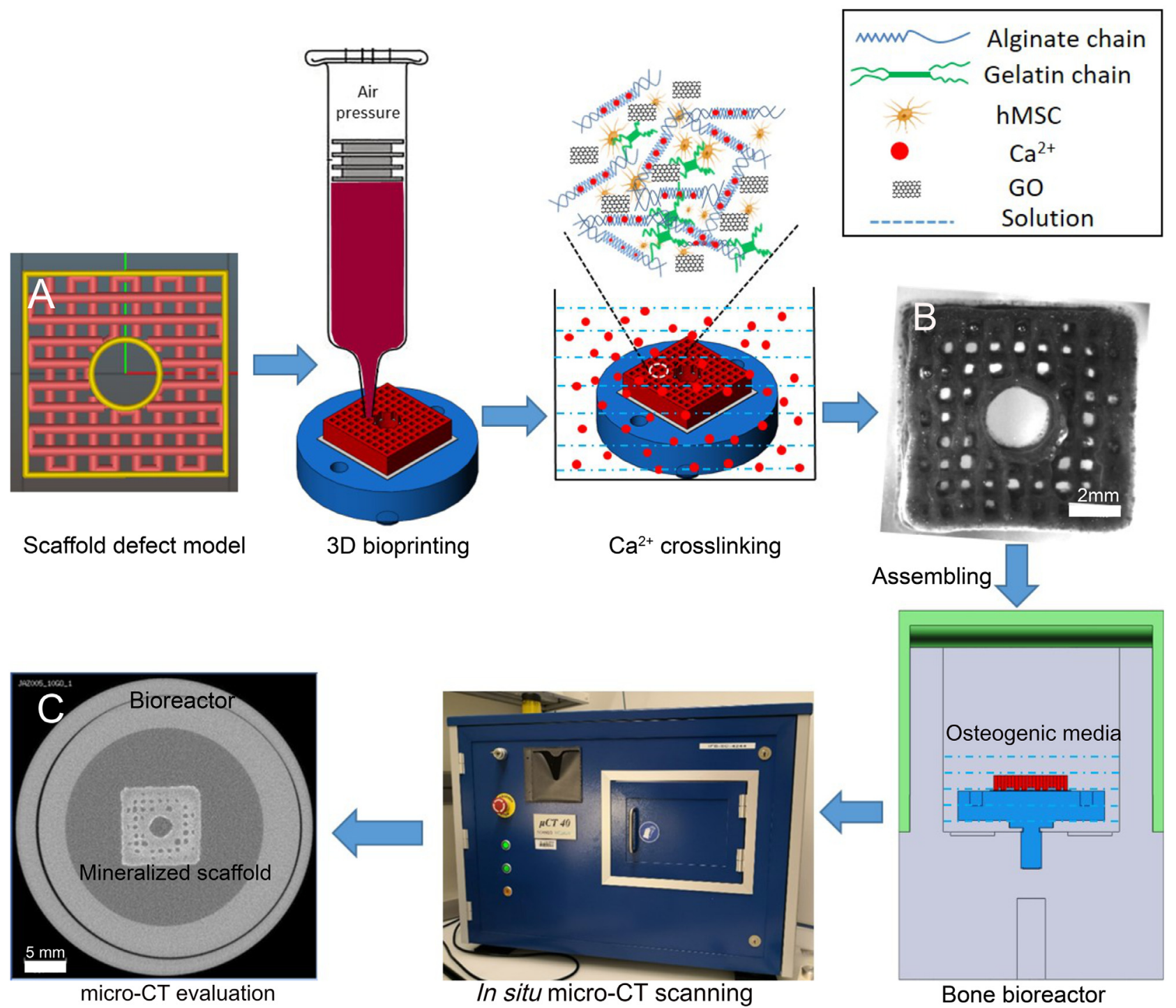

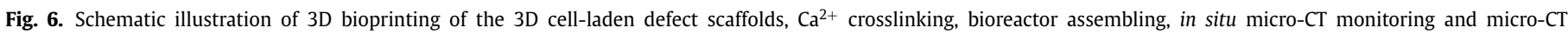

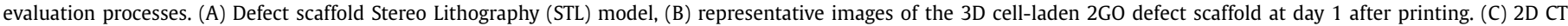
slide image after culture in osteogenic media for 42 days.

\subsection{In situ micro-CT monitoring of mineral formation in $3 D$ bioprinted cell-laden defect scaffolds}

One of the aims of our study is to fabricate 3D cell-laden mineralized scaffolds to mimic the critical-size bone defect model in rodents using a 3D bioprinting technique. 3D hMSC-laden defect scaffolds were bioprinted with different GO incorporations and were cultured in the bone bioreactors for up to 42 days. The influence of different GO concentrations on mineral formation and scaffold fidelity were investigated overtime by in situ time-lapse micro-CT imaging. Scaffolds were mineralized over time, and 2D mineralized slices could be visualized under micro-CT scanning after culture in osteogenic media for 42 days (Fig. 6C). Fig. 7A shows the $3 \mathrm{D}$ reconstructed time-lapsed micro-CT images in the top view of the 3D bioprinted cell-laden defect scaffolds with different GO concentrations. On day 7, there was almost no mineral formation in any group. After culturing in osteogenic media for 42 days, mineralized 3D defect scaffolds were formed. The mineral formation of 3D bioprinted acellular GO scaffolds in osteogenic media should be the internal control groups, which is a limitation to our study. Previous studies have shown that 3D acellular scaf- folds had some spontaneous mineral formation culture in the bone bioreactor with osteogenic media [28,63]. However, 3D cell-laden 0GO scaffolds had significantly higher mineral volume and could keep better scaffold morphological stability than acellular scaffolds [28]. In line, Liu et al. have demonstrated that GO cannot induce spontaneous mineral formation only after reduction and surface functionalized by polymerization of dopamine [64]. Therefore, in our study, 3D acellular GO/alginate/gelatin scaffolds will have some spontaneous mineral formation, but higher mineral volume should be in 3D hMSCs-laden groups. The cylinder printed in the center of the 3D bioprinted cell-laden defect scaffold remained open and no mineral ingrowth was observed in any of the groups. These results suggest that 3D bioprinted cell-laden defect scaffolds can not heal spontaneously and could lead to nonunion prognosis similar to what we find in critical-sized defect models in animals [65]. The defect scaffold shapes were similar to the hydrogel scaffolds after bioprinting, but the overall scaffold area after 42 days of culture was different for the different GO concentrations. The different results of the defect scaffold morphology were in agreement with the scaffold morphology results of the 3D bioprinted cell-laden scaffolds (Fig. 3). The $1 \mathrm{GO}$ group maintained a better overall area 

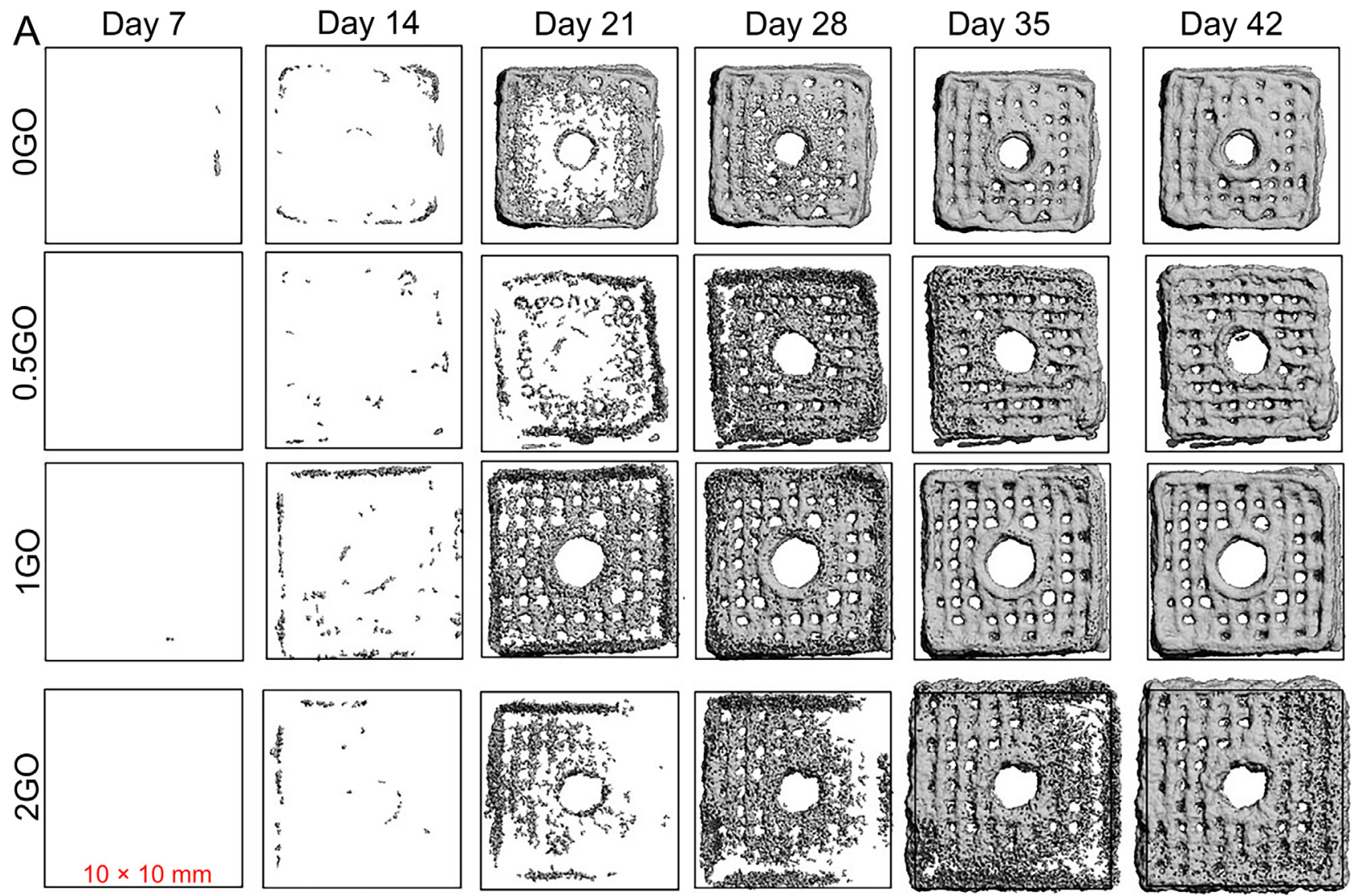

B

\section{Mineral volume}

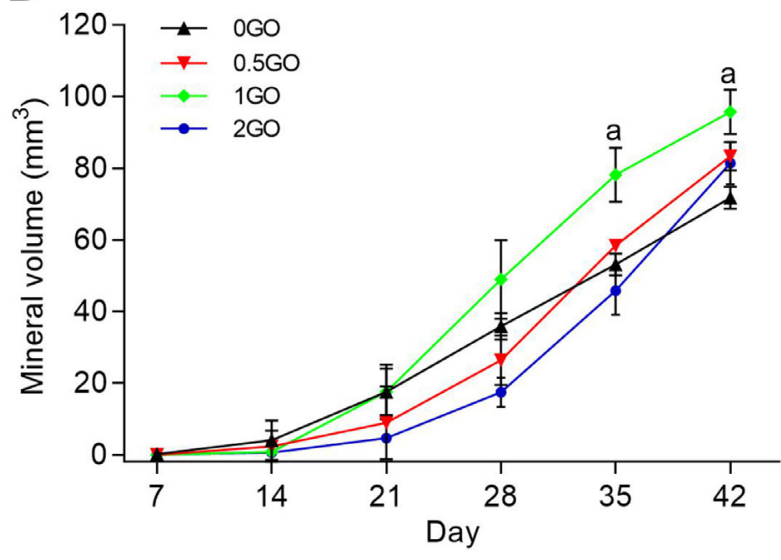

C

\section{Mineral change}

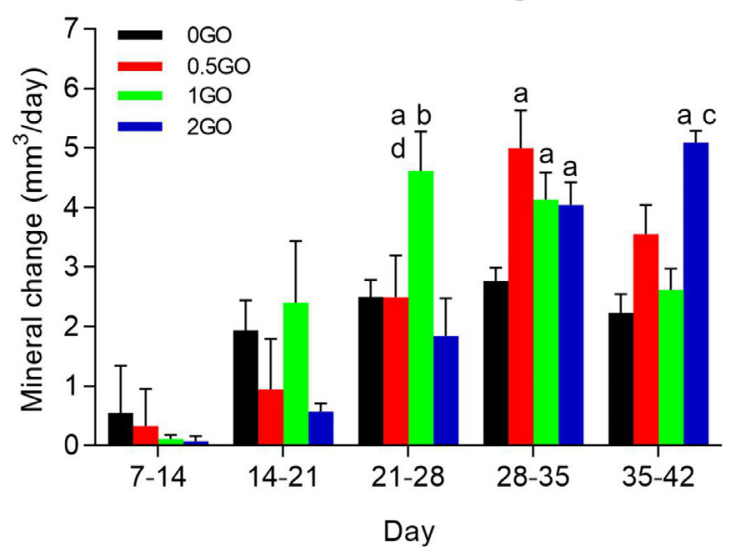

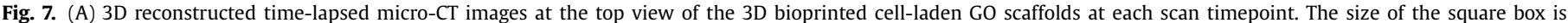

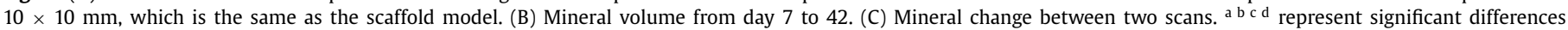
$(\mathrm{P}<0.05)$ compared to 0GO, 0.5GO, $1 \mathrm{GO}$ and $2 \mathrm{GO}$ group, respectively, within the same time point. Data are shown as mean \pm standard deviation $(\mathrm{n}=4)$.

for the defect scaffold morphology than the 0GO group during the 42 days of culture in osteogenic media. Scaffolds in the 0GO group shrank over time, while GO incorporation helped prevent shrinkage and maintain better scaffold fidelity. However, when the GO concentration reached $2 \mathrm{mg} / \mathrm{ml}$, as in the $2 \mathrm{GO}$ group, the defect scaffolds swelled and became larger in size than the designed scaffold model after culturing them in osteogenic media for 28 days. GO absorbed the hydrophilic protein and water molecules in a GO concentration-dependent manner, which may have contributed to the swelling behavior of the $2 \mathrm{GO}$ defect scaffolds.

The quantification of mineral volume in 3D bioprinted cellladen defect scaffolds is shown in Fig. 7B. The mineral volume was similar for all groups on day 14 and increased more than ten-fold from day 14 to day 42 . The mineral volume for the $1 \mathrm{GO}$ scaffolds was $77.4 \pm 7.37 \mathrm{~mm}^{3}$ on day 35 , which was significantly higher than that of the $0 \mathrm{GO}$ scaffolds $\left(56.2 \pm 1.63 \mathrm{~mm}^{3}\right)$. The mineral volumes were $58.5 \pm 0.46 \mathrm{~mm}^{3}$ and $4.58 \pm 5.52 \mathrm{~mm}^{3}$ in the $0.5 \mathrm{GO}$ and $2 \mathrm{GO}$ groups, respectively. On day 42 , the mineral volume was $71.8 \pm 2.63 \mathrm{~mm}^{3}, 83.3 \pm 3.24 \mathrm{~mm}^{3}, 95.7 \pm 5.43 \mathrm{~mm}^{3}$ and $81.5 \pm 4.87 \mathrm{~mm}^{3}$ for the $0 \mathrm{GO}, 0.5 \mathrm{GO}, 1 \mathrm{GO}$ and $2 \mathrm{GO}$ scaffolds, respectively. A significant difference in mineral volume was observed between the $1 \mathrm{GO}$ and $0 \mathrm{GO}$ groups. No significant differences were observed between GO groups on day 42. Furthermore, the mineral changes were calculated every week for all groups (Fig. 7C). The period with the highest mineral change varied among groups. The highest mineral change was first achieved on days 21-28 in 

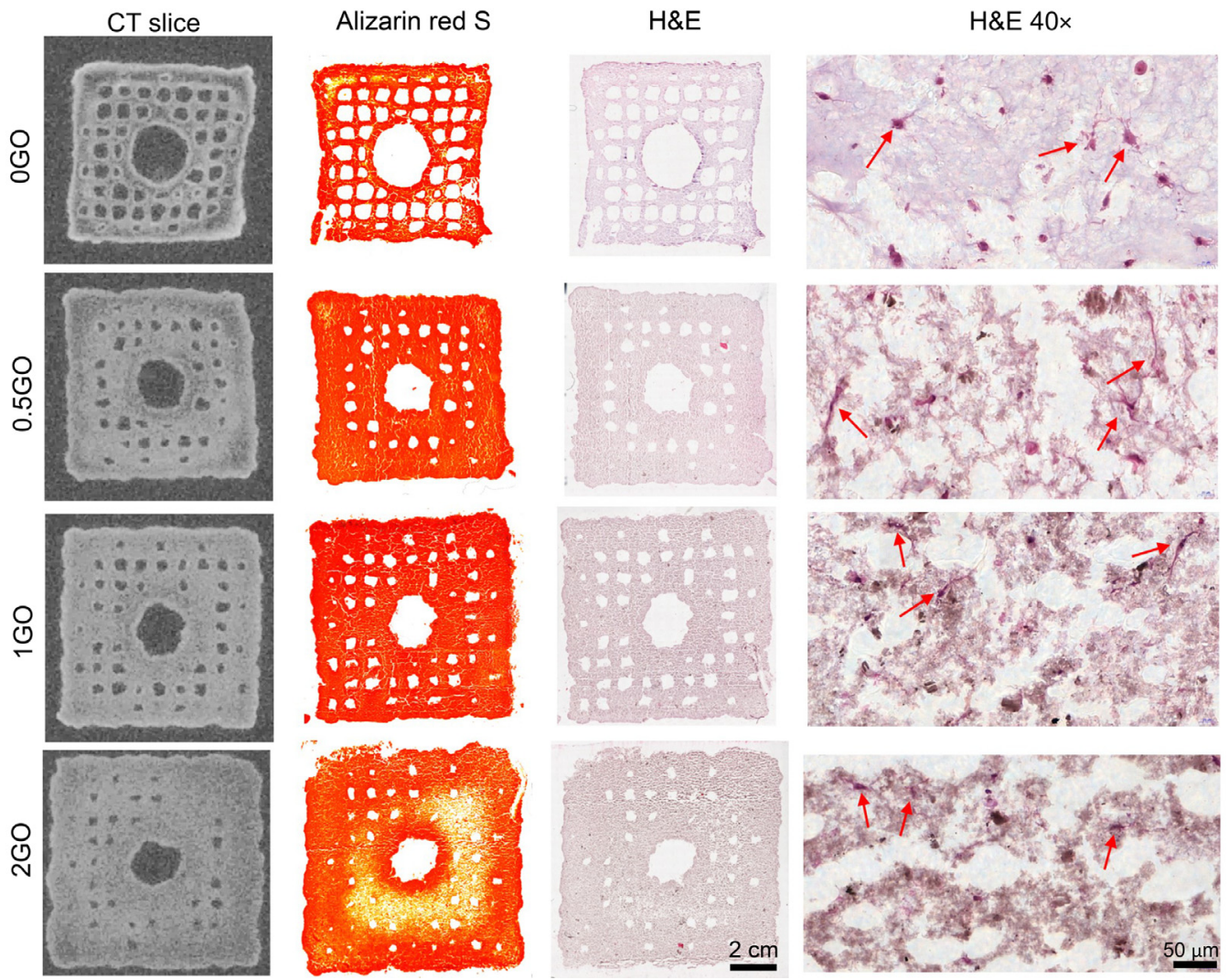

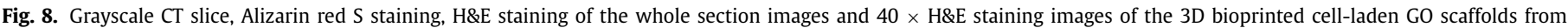
the top region after 42 days of culture in the osteogenic media.

the $1 \mathrm{GO}$ group $\left(4.61 \pm 0.57 \mathrm{~mm}^{3} /\right.$ day), followed by the $0 \mathrm{GO}$ group $\left(2.84 \pm 0.32 \mathrm{~mm}^{3} /\right.$ day $)$ and the $0.5 \mathrm{GO}$ group $\left(5 \pm 0.52 \mathrm{~mm}^{3} /\right.$ day $)$ on days $28-35$. The $2 \mathrm{GO}$ group had the highest mineral change of $5.09 \pm 0.16 \mathrm{~mm}^{3} /$ day on days $35-42$. The mineral change was significantly higher in the $1 \mathrm{GO}$ group than in the other three groups on days $21-28$, and the mineral change was significantly higher in the GO groups compared to the 0GO group on days 28-35.

Consistent with the ALP activity and osteogenic-related gene expression results, the GO concentration was chosen for 3D bioprinting of cell-laden alginate/gelatin defect scaffolds, resulting in enhanced osteogenic differentiation and increased ECM mineralization in osteogenic media. In a previous study, the influence of different cell culture media (control and osteogenic medium) on mineralization was investigated on 3D hMSC-seeded scaffolds. Calcium assay and micro-CT measurement results confirmed that scaffolds cultured in osteogenic medium showed significantly increased calcium contents and mineral volume fraction compared to scaffolds cultured in control medium [63]. Previous investigations have shown that GO composite scaffolds may be able to induce spontaneous osteogenic differentiation of hMSCs in the control medium. Nevertheless, the highest osteogenic differentiation using hMSC was found in the GO group with osteogenic medium [66]. Meanwhile, other groups demonstrated that scaffolds with reduced graphene oxide content better stimulated spontaneous osteogenic differentiation in the control medium [67]. In the future, the osteoinductive potential of GO alone on hMSC could be further investigated and compared to 3D bioprinted hMSCladen GO scaffolds cultured in control medium to assess the individual or the synergistic effect of GO and osteogenic supplements. In the current study, we assumed that although the 3D bioprinted cell-laden GO scaffolds may have the potential to stimulate spontaneous osteogenic differentiation of hMSC already in the control medium, the highest osteogenic differentiation and mineral formation would be in the GO group using the osteogenic medium. Lee et al. [22] demonstrated that GO can increase the extent of mineralization when hMSCs are cultured on a GO substrate by pre-concentrating osteogenic inducers via $\pi-\pi$ stacking. Several studies have shown that GO-modified scaffolds promote new bone formation in bone defects in animal studies $[61,68]$. Ma et al. [61] found that GO-modified $\beta$-tricalcium phosphate (GOTCP) scaffolds significantly promote new bone formation in the bone defects of rabbits compared with pure $\beta$-TCP scaffolds. According to these previous studies, it is reasonable to speculate that the improved ECM mineralization of GO groups is closely related to the negative chemical groups, such as $\mathrm{COO}^{-}$, for nucleation and crystallization of $\mathrm{Ca} / \mathrm{P}$ ions [69]. Due to these chemical groups, increasing GO incorporation will change the scaffold surface roughness. Several studies have shown that cells are influenced by surface chemistry and roughness, which may positively affect cell proliferation, differentiation, and mineralization [70,71]. Mineralized 3D defect scaffolds with embedded human cells have potential applications for use as ex vivo bone models that mimic specific human bone defects. These scaffolds could be used to investigate $e x$ vivo the effectiveness of various biomaterials to repair critical-size bone defects, reducing animal usage in vivo. Our defect mineralized model could also be used to study bone repair in vitro such as inflammation, angiogenesis, cell migration and remodeling. They could also be employed to enable more accurate prediction of therapeutic/toxic responses, again reducing animal usage and further decreasing the cost of drug discovery. Furthermore, in vitro bone models can be developed by fabricating constructs with diseased or dysfunctional human cells for studying patient-specific tissue pathology or testing therapeutics in the context of personalized medicine. 


\subsection{Histology staining}

ECM mineralization and cell morphology in the 3D bioprinted cell-laden GO defect scaffolds were evaluated by Alizarin red S and H\&E staining (Fig. 8) after 42 days of culture with osteogenic media in the bone bioreactor. Histological staining was performed from sections at the top region of the 3D cell-laden GO defect scaffolds. Alizarin red S staining was used to qualitatively visualize the highest mineral region (red) and the lower mineral region (yellow). The Alizarin red S staining images showed that sections taken from the $1 \mathrm{GO}$ scaffolds exhibited denser red staining, which is an indicator of higher mineral content in the 1GO scaffolds as compared to the $0 \mathrm{GO}, 0.5 \mathrm{GO}$ and $2 \mathrm{GO}$ scaffolds. These results were in line with the mineral volume results of the micro-CT evaluation on day 42 . H\&E staining showed a uniform cell distribution throughout the whole section for all groups. Cells spread well in all sections. The cells in the 0GO scaffolds were smaller and showed a narrow and elongated morphology, whereas those in the GO scaffolds were larger and displayed polygonal morphology. We also observed, as shown in Figure S5, that the cytoskeleton of the cells was well organized with abundant stress fibers, which are the contractile bundles of actin filaments in the $1 \mathrm{GO}$ group, while fewer stress fibers were formed in 0GO scaffolds. Some researchers have shown that cell-matrix junctions formed by integrins when cells were grown on surfaces with higher roughness [72]. The results suggest that GO incorporation into 3D bioprinted cell-laden alginate/gelatin scaffolds changed the scaffold roughness, cell adhesion, and cell morphology with more stress fibers.

\section{Conclusion}

3D cell-laden GO/alginate/gelatin composite bone mimicking scaffolds were successfully fabricated using 3D bioprinting technology. The scaffold fidelity of the GO group was better than that of the OGO group, and the compressive modulus increased with increasing GO concentration on day 1 . After 42 days of culture in the osteogenic media, the 0GO scaffolds shrank, and the $1 \mathrm{GO}$ scaffolds maintained the highest-fidelity compared to the scaffolds in the other three groups. The $2 \mathrm{GO}$ group scaffolds swelled and had the lowest compressive modulus. Furthermore, GO provided a certain protective effect, improving cell viability on day 1 and day 7. The biocompatibility properties of GO were further manifested by an increase in the overall cell projected area on day 7 and day 42 of scaffolds of all GO concentrations compared with 0GO scaffolds. Nevertheless, the selected GO concentration is highly relevant for promoting osteoblastic/osteocytic cell differentiation and ECM mineralization. The incorporation of GO at $1 \mathrm{mg} / \mathrm{ml}$ had the highest osteogenic differentiation by upregulating osteogenicrelated gene ( $A L P L, B G L A P, P H E X)$ expression. Interestingly, GO incorporation increased mineral formation in the $3 \mathrm{D}$ bioprinted cellladen defect scaffolds after 42 days of culture in the bioreactor, which was confirmed by in situ micro-CT scanning and histology staining. The 3D bioprinted mineralized defect scaffolds may prove useful as an ex vivo bone mimicking model for critical-sized defects, screening of compounds or the prediction of toxicity, thereby reducing animal usage. In conclusion, the $3 \mathrm{D}$ bioprinted cell-laden scaffolds with $1 \mathrm{mg} / \mathrm{ml}$ GO incorporation improved scaffold fidelity and increased osteogenic differentiation and mineralization, and therefore, these scaffolds have extensive applications in bone model fabrication and bone tissue engineering.

\section{Declaration of Competing Interest}

The authors declare that they have no known competing for financial interests or personal relationships that could have appeared to influence the work reported in this paper.

\section{Acknowledgments}

J. Zhang gratefully acknowledges the financial support from the Chinese Scholarship Council (CSC, No. 201508310116). X.Qin likes to thank ETH Zurich for financial support through a Career Seed Grant (SEED-21 18-2). The authors thank Dr. H.J. Huang from the Laboratory for Multifunctional Materials in ETH Zurich for kindly providing the GO product. The authors thank Dr. Y.Y. Bao from the Drug Formulation \& Delivery group in ETH Zurich for kindly providing the support of rheology measurements. The authors also thank the Scientific Center for Optical and Electron Microscopy (ScopeM) of ETH Zurich for providing the microscopy facilities and the Tissue Engineering and Biofabrication group in ETH Zurich for providing the INKREDIBLE ${ }^{+}$bioprinter.

\section{Supplementary materials}

Supplementary material associated with this article can be found, in the online version, at doi:10.1016/j.actbio.2020.12.026.

\section{References}

[1] H.W. Kang, S.J. Lee, I.K. Ko, C. Kengla, J.J. Yoo, A. Atala, A 3D bioprinting system to produce human-scale tissue constructs with structural integrity, Nat. Biotechnol. 34 (3) (2016) 312-+.

[2] I.T. Ozbolat, M. Hospodiuk, Current advances and future perspectives in extrusion-based bioprinting, Biomaterials 76 (2016) 321-343.

[3] F. Pati, J. Gantelius, H.A. Svahn, 3D Bioprinting of Tissue/Organ Models, Angew. Chem. Int. Ed. Engl. 55 (15) (2016) 4650-4665.

[4] M. Neufurth, X.H. Wang, H.C. Schroder, Q.L. Feng, B. Diehl-Seifert, T. Ziebart, R. Steffen, S.F. Wang, W.E.G. Muller, Engineering a morphogenetically active hydrogel for bioprinting of bioartificial tissue derived from human osteoblastlike SaOS-2 cells, Biomaterials 35 (31) (2014) 8810-8819.

[5] A.C. Daly, G.M. Cunniffe, B.N. Sathy, O. Jeon, E. Alsberg, D.J. Kelly, 3D bioprinting of developmentally inspired templates for whole bone organ engineering, Adv. Healthc. Mater. 5 (18) (2016) 2353-2362.

[6] L.L. Ouyang, C.B. Highley, W. Sun, J.A. Burdick, A generalizable strategy for the 3D bioprinting of hydrogels from nonviscous photo-crosslinkable Inks, Adv. Mater. 29 (8) (2017).

[7] E. Axpe, M.L. Oyen, Applications of alginate-based bioinks in 3D bioprinting, Int. J. Mol. Sci. 17 (12) (2016)

[8] B. Duan, L.A. Hockaday, K.H. Kang, J.T. Butcher, 3D bioprinting of heterogeneous aortic valve conduits with alginate/gelatin hydrogels, J. Biomed. Mater. Res. A 101 (5) (2013) 1255-1264.

[9] Y. Zhao, Y. Li, S. Mao, W. Sun, R. Yao, The influence of printing parameters on cell survival rate and printability in microextrusion-based 3D cell printing technology, Biofabrication 7 (4) (2015) 045002.

[10] J. Zhang, E. Wehrle, J.R. Vetsch, G.R. Paul, M. Rubert, R. Mueller, Alginate dependent changes of physical properties in 3D bioprinted cell-laden porous scaffolds affect cell viability and cell morphology, Biomed. Mater. (2019).

[11] A. Blaeser, D.F.D. Campos, U. Puster, W. Richtering, M.M. Stevens, H. Fischer, Controlling shear stress in $3 \mathrm{D}$ bioprinting is a key factor to balance printing resolution and stem cell integrity, Adv. Healthc. Mater. 5 (3) (2016) 326-333.

[12] Y.X. Luo, C.T. Wu, A. Lode, M. Gelinsky, Hierarchical mesoporous bioactive glass/alginate composite scaffolds fabricated by three-dimensional plotting for bone tissue engineering, Biofabrication 5 (1) (2013).

[13] S. Wust, M.E. Godla, R. Muller, S. Hofmann, Tunable hydrogel composite with two-step processing in combination with innovative hardware upgrade for cell-based three-dimensional bioprinting, Acta Biomater. 10 (2) (2014) 630-640.

[14] T. Jungst, W. Smolan, K. Schacht, T. Scheibel, J. Groll, Strategies and molecular design criteria for 3D printable hydrogels, Chem. Rev. 116 (3) (2016) 1496-1539.

[15] M. Lee, K. Bae, P. Guillon, J. Chang, O. Arlov, M. Zenobi-Wong, Exploitation of cationic silica nanoparticles for bioprinting of large-scale constructs with high printing fidelity, Acs Appl. Mater. Inter. 10 (44) (2018) 37820-37828.

[16] D. Chimene, C.W. Peak, J.L. Gentry, J.K. Carrow, L.M. Cross, E. Mondragon, G.B. Cardoso, R. Kaunas, A.K. Gaharwar, Nanoengineered ionic-covalent entanglement (NICE) bioinks for 3D bioprinting, Acs. Appl. Mater. Inter. 10 (12) (2018) 9957-9968.

[17] J. Yu, W. Ha, J.N. Sun, Y.P. Shi, Supramolecular hybrid hydrogel based on host-guest interaction and its application in drug delivery, Acs. Appl. Mater. Inter. 6 (22) (2014) 19544-19551.

[18] A. Kosik-Koziol, M. Costantini, A. Mroz, J. Idaszek, M. Heljak, J. Jaroszewicz, E. Kijenska, K. Szoke, N. Frerker, A. Barbetta, J.E. Brinchmann, W. Swieszkowski, 3D bioprinted hydrogel model incorporating beta-tricalcium phosphate for calcified cartilage tissue engineering, Biofabrication 11 (3) (2019).

[19] C. Chung, Y.K. Kim, D. Shin, S.R. Ryoo, B.H. Hong, D.H. Min, Biomedical applications of graphene and graphene oxide, Acc. Chem. Res. 46 (10) (2013) 2211-2224. 
[20] S.Y. Park, J. Park, S.H. Sim, M.G. Sung, K.S. Kim, B.H. Hong, S. Hong, Enhanced differentiation of human neural stem cells into neurons on graphene, Adv. Mater. 23 (36) (2011) H263-+.

[21] H. Chen, M.B. Muller, K.J. Gilmore, G.G. Wallace, D. Li, Mechanically strong, electrically conductive, and biocompatible graphene paper, Adv. Mater. 20 (18) (2008) 3557-+.

[22] W.C. Lee, C.H.Y.X. Lim, H. Shi, L.A.L. Tang, Y. Wang, C.T. Lim, K.P. Loh, Origin of enhanced stem cell growth and differentiation on graphene and graphene oxide, Acs. Nano 5 (9) (2011) 7334-7341.

[23] T.R. Nayak, H. Andersen, V.S. Makam, C. Khaw, S. Bae, X.F. Xu, P.L.R. Ee, J.H. Ahn, B.H. Hong, G. Pastorin, B. Ozyilmaz, Graphene for controlled and accelerated osteogenic differentiation of human mesenchymal stem cells, Acs Nano 5 (6) (2011) 4670-4678.

[24] A. Marrella, A. Lagazzo, F. Barberis, T. Catelani, R. Quarto, S. Scaglione, Enhanced mechanical performances and bioactivity of cell laden-graphene oxide/alginate hydrogels open new scenario for articular tissue engineering applications, Carbon 115 (2017) 608-616.

[25] G. Choe, S. Oh, J.M. Seok, S.A. Park, J.Y. Lee, Graphene oxide/alginate composites as novel bioinks for three-dimensional mesenchymal stem cell printing and bone regeneration applications, Nanoscale 11 (48) (2019) 23275-23285.

[26] S. Kang, J.B. Park, T.J. Lee, S. Ryu, S.H. Bhang, W.G. La, M.K. Noh, B.H. Hong, B.S. Kim, Covalent conjugation of mechanically stiff graphene oxide flakes to three-dimensional collagen scaffolds for osteogenic differentiation of human mesenchymal stem cells, Carbon 83 (2015) 162-172.

[27] S.R. Shin, B. Aghaei-Ghareh-Bolagh, T.T. Dang, S.N. Topkaya, X. Gao, S.Y. Yang, S.M. Jung, J.H. Oh, M.R. Dokmeci, X.S. Tang, A. Khademhosseini, Cell-laden microengineered and mechanically tunable hybrid hydrogels of gelatin and graphene oxide, Adv. Mater. 25 (44) (2013) 6385-6391.

[28] J. Zhang, E. Wehrle, P. Adamek, G.R. Paul, X.H. Qin, M. Rubert, R. Muller, Optimization of mechanical stiffness and cell density of 3D bioprinted cell-laden scaffolds improves extracellular matrix mineralization and cellular organization for bone tissue engineering, Acta Biomater. (2020).

[29] S. Hofmann, H. Hagenmuller, A.M. Koch, R. Muller, G. Vunjak-Novakovic, D.L. Kaplan, H.P. Merkle, L. Meinel, Control of in vitro tissue-engineered bonelike structures using human mesenchymal stem cells and porous silk scaffolds, Biomaterials 28 (6) (2007) 1152-1162.

[30] H. Hagenmueller, S. Hofmann, T. Kohler, H.P. Merkle, D.L. Kaplan, G. Vunjak-Novakovic, R. Mueller, L. Meinel, Non-invasive time-lapsed monitoring and quantification of engineered bone-like tissue, Ann. Biomed. Eng. 35 (10) (2007) 1657-1667.

[31] J.R. Vetsch, R. Muller, S. Hofmann, The influence of curvature on three-dimensional mineralized matrix formation under static and perfused conditions: an in vitro bioreactor model, J. R. Soc. Interface 13 (123) (2016).

[32] J.R. Vetsch, D.C. Betts, R. Muller, S. Hofmann, Flow velocity-driven differentiation of human mesenchymal stromal cells in silk fibroin scaffolds: a combined experimental and computational approach, PLoS One 12 (7) (2017).

[33] N.A. Dyment, X. Jiang, L. Chen, S.H. Hong, D.J. Adams, C. Ackert-Bicknell, D.G. Shin, D.W. Rowe, High-throughput, multi-image cryohistology of mineralized tissues, Jove-J Vis Exp (115) (2016).

[34] Y.Q. He, N.N. Zhang, Q.J. Gong, H.X. Qiu, W. Wang, Y. Liu, J.P. Gao, Alginate/graphene oxide fibers with enhanced mechanical strength prepared by wet spinning, Carbohyd. Polym. 88 (3) (2012) 1100-1108.

[35] T.M. Valentin, A.K. Landauer, L.C. Morales, E.M. DuBois, S. Shukla, M. Liu, L.H.S. Valentin, C. Franck, P.Y. Chen, I.Y. Wong, Alginate-graphene oxide hydrogels with enhanced ionic tunability and chemomechanical stability for light-directed 3D printing, Carbon 143 (2019) 447-456.

[36] C.K. Kuo, P.X. Ma, Maintaining dimensions and mechanical properties of ionically crosslinked alginate hydrogel scaffolds in vitro, J. Biomed. Mater. Res. Part A 84a (4) (2008) 899-907.

[37] F.Y. Hsieh, H.H. Lin, S.H. Hsu, 3D bioprinting of neural stem cell-laden thermoresponsive biodegradable polyurethane hydrogel and potential in central nervous system repair, Biomaterials 71 (2015) 48-57.

[38] P.J. Shi, P.F. He, T.K.H. Teh, Y.S. Morsi, J.C.H. Goh, Parametric analysis of shape changes of alginate beads, Powder Technol. 210 (1) (2011) 60-66.

[39] O. Smidsrod, G. Skjakbraek, Alginate as immobilization matrix for cells, Trends Biotechnol. 8 (3) (1990) 71-78.

[40] K.Y. Lee, D.J. Mooney, Alginate: properties and biomedical applications, Prog. Polym. Sci. 37 (1) (2012) 106-126.

[41] G.K. Ramesha, A.V. Kumara, H.B. Muralidhara, S. Sampath, Graphene and graphene oxide as effective adsorbents toward anionic and cationic dyes, J. Colloid. Interf. Sci. 361 (1) (2011) 270-277.

[42] W.B. Hu, C. Peng, M. Lv, X.M. Li, Y.J. Zhang, N. Chen, C.H. Fan, Q. Huang, Protein corona-mediated mitigation of cytotoxicity of graphene oxide, Acs Nano 5 (5) (2011) 3693-3700.

[43] H. Zhao, R.H. Ding, X. Zhao, Y.W. Li, L.L. Qu, H. Pei, L. Yildirimer, Z.W. Wu, W.X. Zhang, Graphene-based nanomaterials for drug and/or gene delivery, bioimaging, and tissue engineering, Drug Discov. Today 22 (9) (2017) 1302-1317.

[44] S. Goenka, V. Sant, S. Sant, Graphene-based nanomaterials for drug delivery and tissue engineering, J. Control. Release 173 (2014) 75-88.

[45] J.C. Fan, Z.X. Shi, M. Lian, H. Li, J. Yin, Mechanically strong graphene oxide/sodium alginate/polyacrylamide nanocomposite hydrogel with improved dye adsorption capacity, J. Mater. Chem. A 1 (25) (2013) 7433-7443.

[46] C.G. Armstrong, V.C. Mow, Variations in the intrinsic mechanical properties of human articular cartilage with age, degeneration, and water content, J. Bone. Joint Surg. Am. 64 (1) (1982) 88-94.
[47] A. Memic, H.A. Alhadrami, M.A. Hussain, M. Aldhahri, F. Al Nowaiser, F. AlHazmi, R. Oklu, A. Khademhosseini, Hydrogels 2.0: improved properties with nanomaterial composites for biomedical applications, Biomed. Mater. 11 (1) (2015) 014104

[48] X. Zhou, M. Nowicki, H.T. Cui, W. Zhu, X.Q. Fang, S.D. Miao, S.J. Lee, M. Keidar, L.J.G. Zhang, 3D bioprinted graphene oxide-incorporated matrix for promoting chondrogenic differentiation of human bone marrow mesenchymal stem cells, Carbon 116 (2017) 615-624.

[49] S. Kermani, R.M.A. Wahab, I.Z.Z. Abidin, Z.Z. Ariffin, S. Senafi, S.H.Z. Ariffin, Differentiation capacity of mouse dental pulp stem cells into osteoblasts and osteoclasts, Cell J. 16 (1) (2014) 31-42.

[50] Z.K. Kuo, P.L. Lai, E.K.W. Toh, C.H. Weng, H.W. Tseng, P.Z. Chang, C.C. Chen, C.M. Cheng, Osteogenic differentiation of preosteoblasts on a hemostatic gelatin sponge, Sci. Rep. 6 (2016).

[51] H.H. Yoon, S.H. Bhang, T. Kim, T. Yu, T. Hyeon, B.S. Kim, Dual roles of graphene oxide in chondrogenic differentiation of adult stem cells: cell-adhesion substrate and growth factor-delivery carrier, Adv. Funct. Mater. 24 (41) (2014) 6455-6464.

[52] Y. Wang, W.C. Lee, K.K. Manga, P.K. Ang, J. Lu, Y.P. Liu, C.T. Lim, K.P. Loh, Fluorinated graphene for promoting neuro-induction of stem cells, Adv. Mater. 24 (31) (2012) 4285-4290.

[53] S. Namgung, T. Kim, K.Y. Baik, M. Lee, J.M. Nam, S. Hong, Fibronectin-carbonnanotube hybrid nanostructures for controlled cell growth, Small 7 (1) (2011) 56-61.

[54] M. Mazaheri, O. Akhavan, A. Simchi, Flexible bactericidal graphene oxide-chitosan layers for stem cell proliferation, Appl. Surf. Sci. 301 (2014) 456-462.

[55] O. Akhavan, E. Ghaderi, A. Akhavan, Size-dependent genotoxicity of graphene nanoplatelets in human stem cells, Biomaterials 33 (32) (2012) 8017-8025.

[56] M. Mizuno, Y. Kuboki, Osteoblast-related gene expression of bone marrow cells during the osteoblastic differentiation induced by type I collagen, J. Biochem. (Tokyo) 129 (1) (2001) 133-138.

[57] A. Infante, C.I. Rodríguez, Osteogenesis and aging: lessons from mesenchymal stem cells, Stem Cell Res. Therapy 9 (1) (2018) 244.

[58] M.C. Chen, Y.C. Sun, Y.H. Chen, Electrically conductive nanofibers with highly oriented structures and their potential application in skeletal muscle tissue engineering, Acta Biomater. 9 (3) (2013) 5562-5572.

[59] S. Ryu, B.S. Kim, Culture of neural cells and stem cells on graphene, Tissue Eng. Regen. Med. 10 (2) (2013) 39-46.

[60] D. Bhadra, J. Sannigrahi, B.K. Chaudhuri, H. Sakata, Enhancement of the transport and dielectric properties of graphite oxide nanoplatelets-polyvinyl alcohol composite showing low percolation threshold, Polym. Compos. 33 (3) (2012) 436-442.

[61] H.S. Ma, C.A. Jiang, D. Zhai, Y.X. Luo, Y. Chen, F. Lv, Z.F. Yi, Y. Deng, J.W. Wang, J. Chang, C.T. Wu, A bifunctional biomaterial with photothermal effect fortumor therapy and bone regeneration, Adv. Funct. Mater. 26 (8) (2016) 1197-1208.

[62] A.X. Wang, K.F. Pu, B. Dong, Y. Liu, L.M. Zhang, Z.J. Zhang, W. Duan, Y.M. Zhu, Role of surface charge and oxidative stress in cytotoxicity and genotoxicity of graphene oxide towards human lung fibroblast cells, J. Appl. Toxicol. 33 (10) (2013) 1156-1164.

[63] J.R. Vetsch, S.J. Paulsen, R. Muller, S. Hofmann, Effect of fetal bovine serum on mineralization in silk fibroin scaffolds, Acta Biomater. 13 (2015) 277-285.

[64] H.Y. Liu, P.X. Xi, G.Q. Xie, Y.J. Shi, F.P. Hou, L. Huang, F.J. Chen, Z.Z. Zeng, C.W. Shao, J. Wang, Simultaneous reduction and surface functionalization of graphene oxide for hydroxyapatite mineralization, J. Phys. Chem. C 116 (5) (2012) 3334-3341.

[65] M.M. Martino, P.S. Briquez, E. Guc, F. Tortelli, W.W. Kilarski, S. Metzger, J.J. Rice, G.A. Kuhn, R. Muller, M.A. Swartz, J.A. Hubbell, Growth factors engineered for super-affinity to the extracellular matrix enhance tissue healing, Science 343 (6173) (2014) 885-888

[66] M. Nair, D. Nancy, A.G. Krishnan, G.S. Anjusree, S. Vadukumpully, S.V. Nair, Graphene oxide nanoflakes incorporated gelatin-hydroxyapatite scaffolds enhance osteogenic differentiation of human mesenchymal stem cells, Nanotechnology 26 (16) (2015).

[67] J.H. Lee, Y.C. Shin, O.S. Jin, S.H. Kang, Y.S. Hwang, J.C. Park, S.W. Hong, D.W. Han, Reduced graphene oxide-coated hydroxyapatite composites stimulate spontaneous osteogenic differentiation of human mesenchymal stem cells, Nanoscale 7 (27) (2015) 11642-11651.

[68] C.T. Wu, L.G. Xia, P.P. Han, M.C. Xu, B. Fang, J.C. Wang, J. Chang, Y. Xiao, Graphene-oxide-modified beta-tricalcium phosphate bioceramics stimulate in vitro and in vivo osteogenesis, Carbon 93 (2015) 116-129.

[69] S. Kim, S.H. Ku, S.Y. Lim, J.H. Kim, C.B. Park, Graphene-biomineral hybrid materials, Adv. Mater. 23 (17) (2011) 2009-2014.

[70] Y.F. Chou, W. Huang, J.C. Dunn, T.A. Miller, B.M. Wu, The effect of biomimetic apatite structure on osteoblast viability, proliferation, and gene expression, Biomaterials 26 (3) (2005) 285-295.

[71] S.H. Ku, C.B. Park, Myoblast differentiation on graphene oxide, Biomaterials 34 (8) (2013) 2017-2023.

[72] T.P. Kunzler, T. Drobek, M. Schuler, N.D. Spencer, Systematic study of osteoblast and fibroblast response to roughness by means of surface-morphology gradients, Biomaterials 28 (13) (2007) 2175-2182. 